\title{
A New Analytical Prediction for Energy Responses of Hemi-Cylindrical Shells to Explosive Blast Load
}

\author{
Ping Liu ${ }^{1,2, * \mathbb{D}}$, Ning $\mathrm{Xu}^{1}$ and Zhi-Hong Pan ${ }^{1}$ \\ 1 School of Architecture and Civil Engineering, Jiangsu University of Science and Technology, \\ Zhenjiang 212000, China \\ 2 Department of Civil Engineering, The University of Birmingham, Birmingham B15 2TT, UK \\ * Correspondence: liupinghaiyan@163.com
}

Received: 23 June 2019; Accepted: 5 July 2019; Published: 11 July 2019

\begin{abstract}
This study presents a new analytical model on the dissipation process of the initial total energy of the hemi-cylindrical shell subjected to the explosive blast load. The analytical formulation has been established using the energy method. The analytical predictions have been validated and found to be in excellent agreement with numerical simulations calculated by explicit finite element method (via LS-DYNA). The variational parameters considered are the shell thickness, elastic modulus, densities of the shell, and the positions of the detonation. Considering varieties of the parameters, the analytical and numerical results demonstrate that the pattern of vibrating deformations can be classified into two types according to the detonation positions. If the detonation position was at the midpoint of the width, there was no main frequency, whilst if the detonation position was at the edge of the width, the shell vibrated with a main frequency. It was also found from both analytical and numerical models that the total initial energy is inversely proportional to the thickness of the shell (T), namely, the exact formula can be written as $\beta=\rho_{a} c / \rho_{s} T$. Surprisingly, this study is the first to highlight that the total energy decreases with time by the exponential function, and the exponential ratio $(\beta)$ is inversely proportional to the thickness of the shell as well.
\end{abstract}

Keywords: blast load; hemi-spherical shell; energy decrease principal; energy method; LS-DYNA

\section{Introduction}

Hemi-cylindrical shell structures are used in many applications in ocean engineering, aerospace, composite materials and civil engineering [1-6]. For example, submarine, sea detector, aircraft brakes, ballistic components, gymnasiums, modern libraries, buried gas pipelines, and large span roofs are some of the distinct fields of applications [7-10]. In all these applications, the cylindrically curved panel structures can be subjected to different loading conditions. Due to the increased precision and increased destructive power and lethality of modern weapons, both military structures and some civil structures have become vulnerable to extreme shock loads [11-14]. Therefore, blast load is becoming an important topic. How much energy a shell can absorb become more and more significant so that structural engineers can safely design the shell structures [15-18]. However, little works on the energy responses, especially on the decrease of energy deduced by air damping has been reported to date [19-21].

Cylindrical shells are fundamental parts of large roofs and a wide number of military structures which could be subjected to air blast load [22,23]. Most of them are related to the dynamic response of isotropic shell structures subjected to the blast loads especially with some erosion criteria [24,25]. H. S. Turkmen [26] investigated the dynamic response of steel cylindrical shell panels subjected to air blast load via the assumptions of Love's theory of thin elastic shells. They used a Fourier transformation technique to analyze the blast data. Santosa and Arifurrahman [27] studied the response analysis 
of blast impact load of metal-foam sandwich panels via numerical simulation. In their papers, A parametric studies were carried out by varying panel thickness, specific material and foam density for certain blast loads and impact stand-off distance. Nihal and Kennedy [28-30] researched the dynamic stiffness equations of variable thickness cylindrical shells using Donnell, Timoshenko and Flugge theories. A theoretical formula was derived in his paper. Tang et al. [31] founded an analytical procedure for free vibration analysis of a circular cylindrical shell with arbitrary boundary conditions. Chen and Ye used the Wittrick-Williams [32] algorithm to create a generalized formula with general shaped meridians and arbitrary boundary conditions. Actually, they created a numerical method. Thibaut and Nicolas [33] paid attention to the stability of the shell between static and dynamic buckling. The different failure mode was discussed according to different loading rate.

Some experimental studies are related to shell structures subjected to blast load. Robert and K. Clubley [34] have carried out a long duration blast load experiment of a cylindrical shell structure containing varying fluid levels [35]. J. L. Ma et al. [35] studied the behavior of single-layer lattice shells subjected to confined blast load. Their studies investigated the effect of scaled distance, the ratio of rise to span, and the ratio of height to span. Emarti and M. K. Singha [36] studied a nonlinear response of cylindrical panels subjected to a parabolical distributed blast load. The effects of the ratio of span to thickness, radius to span and peak pressure were developed comprising Tsai-Wu quadratic failure criterion.

Unfortunately, few studies which were devoted to the theoretical and experimental results of the blast-loaded cylindrical shell structures can be found in the literatures [37-39]. In fact, there are few publications of research on the air damping up to date [40,41]. Therefore, this study is the first to establish the combination of theoretical study and numerical simulations in order to investigate the hemi-cylindrical shell exposed to the explosive blast shock wave. Numerical simulations were carried out using an explicit finite element method (LS-DYNA) to verify the theoretical predictions of energy decrease contributed by the air damping. The mathematical model of the hemi-cylindrical shell subjected to a blast load has been established by using the energy-based Donnell's theory alongside the modified theory of the damping forces. In addition, LS-DYNA software is utilized to obtain the energy data numerically [42-44]. LS-DYNA results were compared with analytical results and excellent agreement can be observed. According to the traditional approach in the design, there is no analytical method to estimate the precise value of air damping. This study enables a novel analytical prediction formulation that can be practically utilized in design and analysis of hemi-cylindrical shell structures exposed to the explosive blast load. This new mathematical technique will reduce significantly the time to calculate the energy responses of the structure in comparison with the numerical modeling.

\section{Systems of Motion}

The geometry of the hemi-cylindrical shells with simple supports at both longitude end was investigated in this work. The equation of motion [45] is listed in Equation (1):

$$
\left\{\begin{array}{l}
\Gamma^{2} \phi+D \nabla^{4} \omega+\rho_{s} t \omega^{\prime \prime}=p \\
\frac{1}{E t} \nabla^{4} \phi-\Gamma^{2} \omega=0
\end{array}\right.
$$

where, $\phi, \omega$ represent the Airy's function on the membrane force and the normal displacement, respectively, $D=E T^{3} / 12\left(1-v^{2}\right), \rho_{s}, T$ the stiffness, density, and thickness of the shell, respectively. $E$ is the elastic modulus, $p$ pressure acted upon the shell, $\nabla, \Gamma^{2}$ are defined as $\nabla=\frac{\partial}{\partial x} i+\frac{\partial}{\partial x} j$, $\Gamma^{2}=\frac{1}{r_{x}} \frac{\partial}{\partial x^{2}}+\frac{1}{r_{s}} \frac{\partial}{\partial s^{2}}$, respectively. In the specific case of cylindrical shells, $\Gamma^{2}=\frac{1}{R} \frac{\partial}{\partial x^{2}}$. The 1 st and 2 nd terms are taken into account as the B-surface force or S-surface force. According to the theory of Donnell-Mushtari, $\Gamma^{2} \phi$ expresses the normal pressure contributed from the extension of the middle surface which is the so-called membrane force or B-surface force, and $D \nabla^{4} \omega$ expresses the normal pressure contributed from the curvature of the middle surface which is the so-called moment force or S-surface force. The diagram of geography and coordinate is shown in Figure 1. 


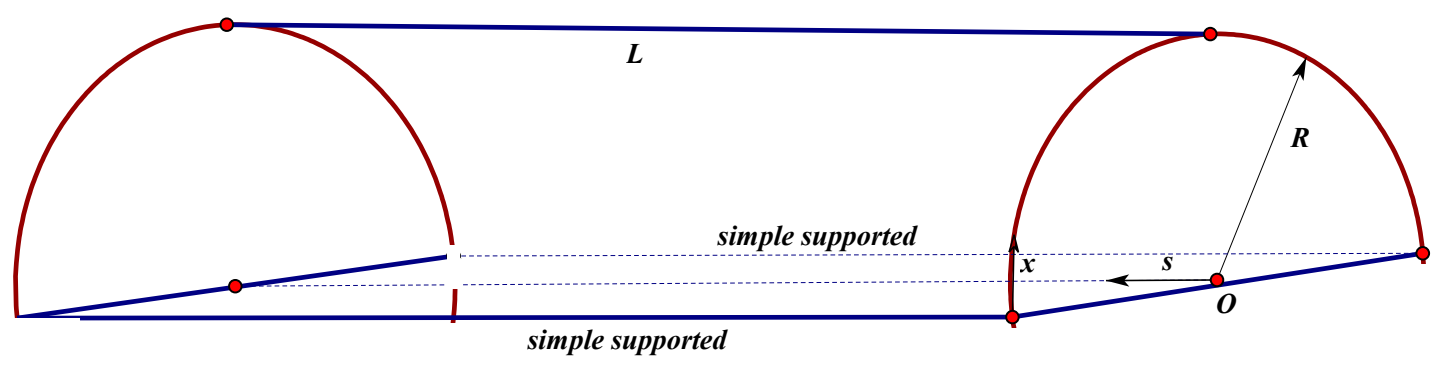

Figure 1. The diagram of a cylindrical coordinate.

\subsection{Frequency Analysis}

When the free vibration is considered, both $\phi$ and $\omega$ can be assumed as a harmonic function with the same frequency $\omega_{0}$. Meanwhile, the shell can be assumed to vibrate in an $n$-th half wave along the length and an $m$-th half wave along the semi-circular arc. So, it can be concluded that $[28,46]$,

$$
\left\{\begin{array}{l}
\omega=A \cdot \sin \left(\frac{n \pi}{S} x\right) \cos \left(\frac{m \pi}{L} s\right) \cos \left(\omega_{0} t\right) \\
\phi=B \cdot \sin \left(\frac{n \pi}{S} x\right) \cos \left(\frac{m \pi}{L} s\right) \cos \left(\omega_{0} t\right)
\end{array}\right.
$$

where, $S=\pi R=\alpha L$, donate the length along the hemi circular arc, $L$ is the length of the cylindrical shell and $A, B$ is a coefficient, respectively. Therefore, the following statement is true according to the 2nd term of Equation (2),

$$
\nabla^{4}=\left(\frac{n^{2}}{S^{2}}+\frac{m^{2}}{L^{2}}\right)^{2} \phi=\frac{E T}{R^{2}} \cdot \frac{n^{2}}{S^{2}} \omega \Rightarrow \phi=\frac{E T}{R^{2}} \cdot \frac{n^{2} S^{2}}{\left(n^{2}+\alpha^{2} m^{2}\right)^{2}} \omega .
$$

By Substituting Equation (3) to the first term of Equation (1) without any pressure acting on the shell, the Equation (2) may be simplified as Equation (4) shown below,

$$
\frac{E T}{R^{4}} \cdot \frac{n^{2} S^{2}}{\left(n^{2}+\alpha^{2} m^{2}\right)^{2}} \omega+D \nabla^{4} \omega+\rho_{s} T \cdot \omega^{\prime \prime}=0 .
$$

As for the natural frequencies, it may be derived after substituting Equation (2) into Equation (4),

$$
\omega_{0}^{2}=\frac{1}{\rho_{s}}\left\{\frac{E}{R^{4}} \frac{n^{2} S^{2}}{\left(n^{2}+\alpha^{2} m^{2}\right)^{2}}+\frac{D \pi^{4}}{T}\left(\frac{n^{2}}{S^{2}}+\frac{m^{2}}{L^{2}}\right)^{2}\right\},
$$

If denote symbols, $\Omega^{2}=\frac{\rho_{s} R^{2}\left(1-v^{2}\right)}{E} \omega^{2}, k=\frac{T^{2}}{12 R^{2}}$, the dimensionless symbol value can be deducted below as Equation (6),

$$
\Omega^{2}=\frac{\pi^{2} n^{2}\left(1-v^{2}\right)}{\left(n^{2}+\alpha^{2} m^{2}\right)^{2}}+k\left(n^{2}+\alpha^{2} m^{2}\right)^{2} .
$$

If only circumferential modes are considered, $m=0$ and Equation (6) may be simplified as,

$$
\Omega^{2}=\left\{\frac{\pi^{2}\left(1-v^{2}\right)}{n^{2}}+k n^{4}\right\},
$$

while the classical frequency formula derived from Donnell's theory is shown as Equation (8),

$$
\Omega^{2}=\frac{1}{2}\left\{1+n^{2}+k\left(n^{2}-1\right)-\sqrt{\left(1+n^{2}+k\left(n^{2}-1\right)\right)^{2}-4 k \cdot n^{2}(n-1)^{2}}\right\} .
$$

Figure 2 reveals the comparison of frequencies calculated from classical formula and this paper. The frequency predictions of this paper and Donnell's theory are in excellent agreement since the 4th 
order mode has less than $5 \%$ deviation. In addition, the Equation (7) is a new modified mathematical technique, which is simpler in a practical form and can be applied to calculate the frequency of 3-D model whilst the Donnell's formula can be applied to the 2-D model only.

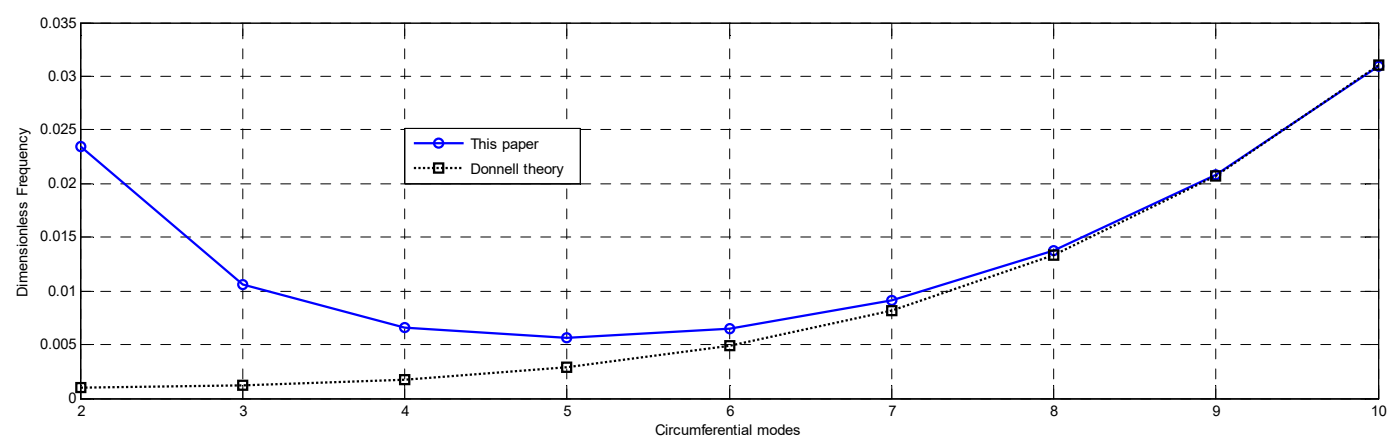

Figure 2. Frequency comparison between this study and Donnell's theory.

\subsection{Relationship between Energy and Position}

The pressure impulse $[47,48]$ can be calculated as follows,

$$
I=200 q^{2 / 3} / r
$$

Thus, the total energy absorbed in the blast event by the shell is proportional to the impulse multiplying by pressure area. Considering that the position of detonation is at the midpoint of the width, Figure 3 shows the schematic diagram for the calculation of energy caused by blast impulse.

$$
E_{e} \propto \int_{0}^{L} I \cdot d s \propto \int_{s 1}^{s 2} \frac{R}{R^{2}+(z-z 0)^{2}} d s \propto 200 q^{2 / 3}\left\{a \tan \left(\frac{L-z 0}{R}\right)+a \tan \left(\frac{z 0}{R}\right)\right\},
$$

where, $E_{e}$ denote the total energy. Let $z=z 0 / L, r=R / L$, the solution can be deduced as

$$
E_{e} \propto 200 q^{2 / 3}\left\{a \tan \left(\frac{1-z}{r}\right)+a \tan \left(\frac{z}{r}\right)\right\} .
$$

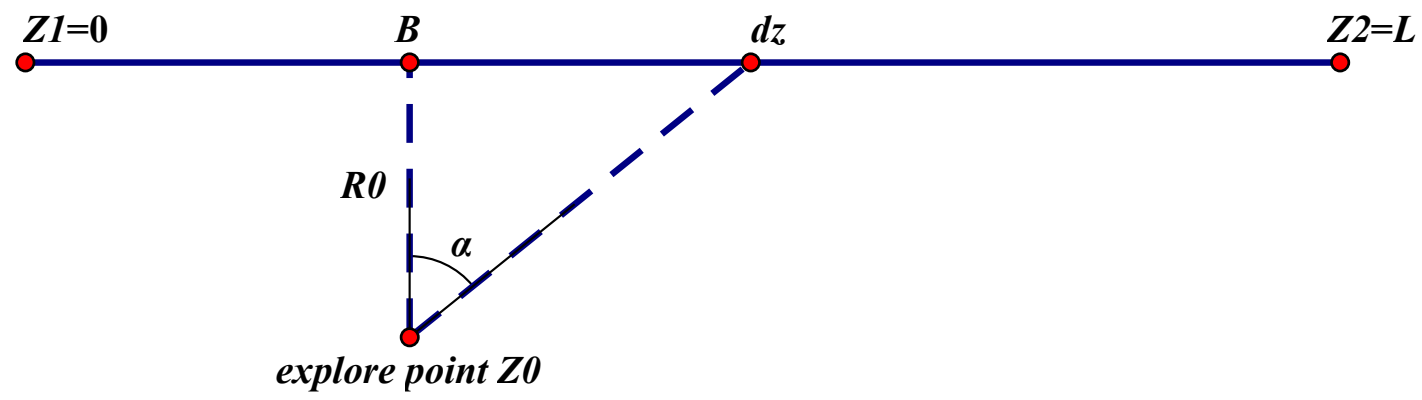

Figure 3. The calculation sketch of energy when detonation is in the middle along the width.

According to the Equation (10), the total energy $E_{e}$ will reach the value of max at $z=0.5$, where the position is just at the midpoint of longitude of the shell exactly. The coefficient should be determined by the configuration, thickness, and material of the shell. 


\subsection{Energy Analysis of the Damping Load}

The air damping in the vibrating shell can be predicted as $\rho_{d} \omega^{\prime}$, where $\rho_{d}$ is the density of air. Thus, If the damping force is taken into account, the free vibration of Equation (4) may be rewritten as Equation (11) below by adding damping force,

$$
\frac{E t}{R^{4}} \frac{n^{2} S^{2}}{\left(n^{2}+\alpha^{2} m^{2}\right)^{2}} \omega+D \nabla^{4} \omega+\rho_{s} T \omega^{\prime \prime}+\rho_{d} \omega^{\prime}=0 .
$$

The energy contributed from the damping load is,

$$
E_{d}=\rho_{d} \int_{0}^{t} d t \int_{\Omega} v^{2} d s
$$

And the kinetic energy of the shell structure can be obtained as,

$$
E_{k}=\frac{1}{2} \rho_{s} T \int_{\Omega} v^{2} d s
$$

Therefore, it may be obtained finally,

$$
E_{d}=\beta \int_{0}^{t} E_{k} d t \text { or } \frac{d E_{d}}{d t}=\beta E_{k}, \text { where } \frac{2 \rho_{d}}{\rho_{s} T}=\beta .
$$

Due to the principle of energy conversion, the internal energy and kinetic energy of shell transfer to each other in the procedure of vibration. The maximum value of energy in both internal energy and kinetic energy is equivalent with a few differences between phases. As for the high frequency in the procedure of blast, it is reasonable to assume the internal energy of the shell be equal to the kinetic energy. According to the conservation of energy laws, it may be concluded that,

$$
2 E_{d}+E_{k}+E_{i}=E_{0}
$$

where, $E_{0}$ is a constant denoting the total initial energy. Substituted with the relationship of Equation (12), it can be obtained that, $\beta \int_{0}^{t} E_{k} d t+E_{k}=E_{0}$, finally, the solution can be derived,

$$
E_{k}=E_{0} e^{-\beta t} .
$$

The solution of Equation (14) shows that after a short blast duration, the shell will absorb a certain degree of energy which is equivalent to $E_{0}$ which will decrease by the exponential function with the exponential ratio $\beta$.

Nevertheless, kinetic energy is not equal to internal energy sometimes. As described below, the energy decreases by the exponential function and there is a phase difference between the internal energy and the kinetic energy. Therefore, taking account into such difference, it is reasonable to assume that [49],

$$
E_{i}=E_{k}-A e^{-\alpha t} \sin \left(\omega_{0} t+\varphi\right)
$$

where, $A$ is the amplitude, $\alpha$ the exponential ratio, both of which can be determined by the geometry configuration, material of the shell and the position of blast detonation. $\varphi$ is the difference of phase between the internal energy and kinetic energy. Thus, the conservation equation may be rewritten as,

$$
2 E_{d}+2 E_{k}-A e^{-a t} \sin \left(\omega_{0} t+\varphi_{0}\right)=E_{0} .
$$


The theoretical solution can be concluded as,

$$
E_{k}=E_{0} e^{-\beta t}+\frac{\bar{A}}{2} \frac{e^{-\alpha t} \sin \left(\omega_{0} t+\varphi_{0}\right)}{(b+\beta)^{2}+\omega_{0}^{2}},
$$

where, $\bar{A}=A \sqrt{\left(b^{2}-b \beta+\omega_{0}^{2}\right)^{2}+\beta^{2} \omega_{0}^{2}}, \tan \left(\varphi_{0}\right)=\left(b^{2}-b \beta+\omega_{0}^{2}\right) / \beta \omega_{0}$. When the frequency $\omega_{0}$ is large, the solution can be simplified as Equation (17),

$$
E_{k}=E_{0} e^{-\beta t} .
$$

The formula Equation (17) is identical to Equation (14) exactly. Whilst the vibration frequency $\omega_{0}$ is small, $\sin \left(\omega_{0} t+\varphi_{0}\right)$ may be treated as a constant value in the limit range. So, the solution can be simplified,

$$
E_{k}=E_{1} e^{-\beta t}+E_{2} e^{-\alpha t}
$$

where $E_{1}+E_{2}=E_{0}$, is the initial total energy of shell after blast procedure and $E_{1}-E_{2}$ should be fixed by the configuration and properties of the model.

\subsection{Pressure Load}

Contributed by lots of experiments, there are several blast models for numerical calculation of blast load. The Brode model $[50,51]$ does not account for the angle of incidence of the blast wave on the surface of the structure. The CONWEP algorithms [52] however considered the angle by combining the reflected pressure (normal-incidence) value and the incident pressure (side-on incidence) value which is also the method that LS-DYNA accepts. The pressure load is calculated by Equation (19) by using the keywords *LOAD_BLAST_SEGMENT_SET and *LOAD_BLAST_ENHANCED in LS-DYNA software [53,54].

$$
P_{\text {inc }}=P_{S}(1-\tau) e^{-a \tau}, \tau=\frac{t-t_{a}}{t_{+}-t_{a}}
$$

Figure 4 presents the pattern of blast load from Equation (19) and the results obtained from numerical simulation. It can be seen that the shape of pressure vs. time from both theory and simulation are the same. The peak pressure is determined by both the position and the mass of detonation. In addition, the velocity of the blast is more than $1000 \mathrm{~m} / \mathrm{s}$ so that there is some time delay in the different position when the blast reaches.

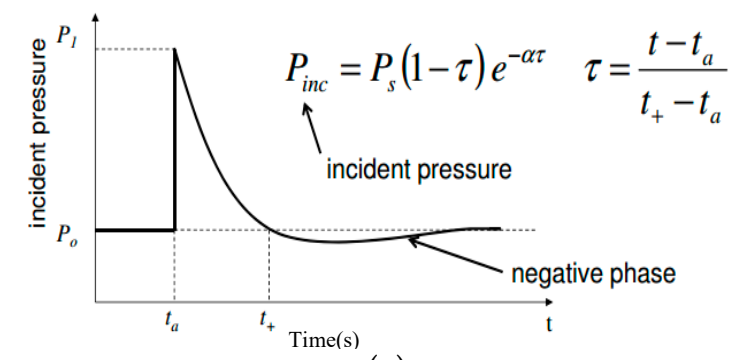

(a)

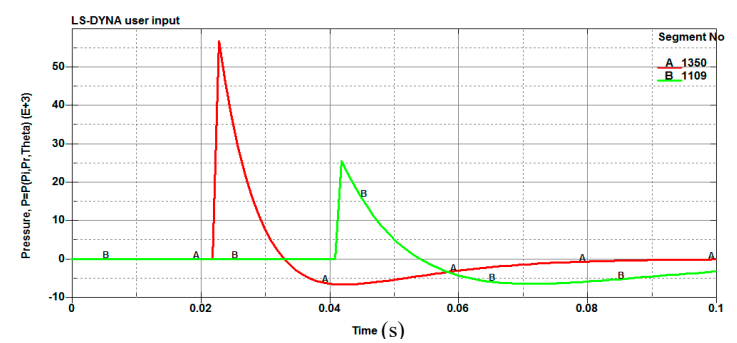

(b)

Figure 4. The plot of pressure vs. time in theory and numerical simulation. (a) The pattern of blast load, (b) The time history of blast load in simulation

\subsection{Numerical Verification}

To verify the numerical method, the simulations of the experiments in the studies [55] have been carried out again via the commercial software LS-DYNA (incensed by ANSYS 19.0). The model was a rectangle membrane vibrating under a collision load. The membrane is made of Heytex H5474 and the geometry details are shown in Figure 5a. Besides, the blast load is simulated by a sphere bullet acting 
upon at the center of the membrane labeled as point $\mathrm{C} 1$. Figure $5 \mathrm{~b}$ shows the corresponding numerical model where the air element is hidden. In the model, the grid size of shell was $10 \mathrm{~mm}$ and that of bullet is $5 \mathrm{~mm}$. There are 39,071 quadrilateral elements after meshing. The bullet was then simulated as a sphere with the same radius and density to the bullet. In order to consider the effect of the air, it was assumed to be an elastic material with a density of $1.225 \mathrm{~kg} / \mathrm{m}^{3}$, bulk module $101,325 \mathrm{~Pa}$.

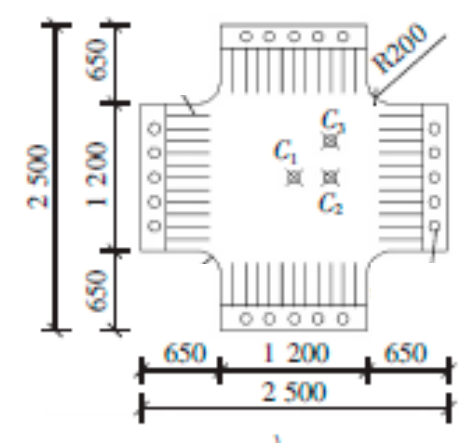

(a)

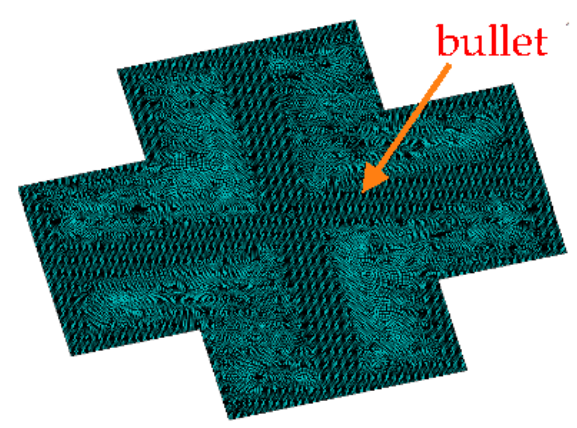

(b)

Figure 5. The experiment model and the numerical model. (a) Experiment geometry model (mm).

(b) Numerical model with hiding air element.

Figure 6 shows the comparison of displacement time history at $\mathrm{C} 1$ and $\mathrm{C} 2$. The experiment data is expressed in a solid green line with a square and the numerical result is plotted in a dotted blue line with a circle. The cycle time of experiment and simulation is $0.071 \mathrm{~s}$ and $0.072 \mathrm{~s}$ which can be seen as the same value. The correlation coefficient of $C 1$ and $C 2$ are $0.931,0.927$, respectively. If the abscissa value is considered from $0.0 \mathrm{~s}$ to $2.0 \mathrm{~s}$ only, the correlation coefficient can be improved to $0.952,0.962$ respectively. Therefore, it can be concluded that the data fit well and the numerical model can be used to calculate the dynamic response of the shell vibrating in the air.
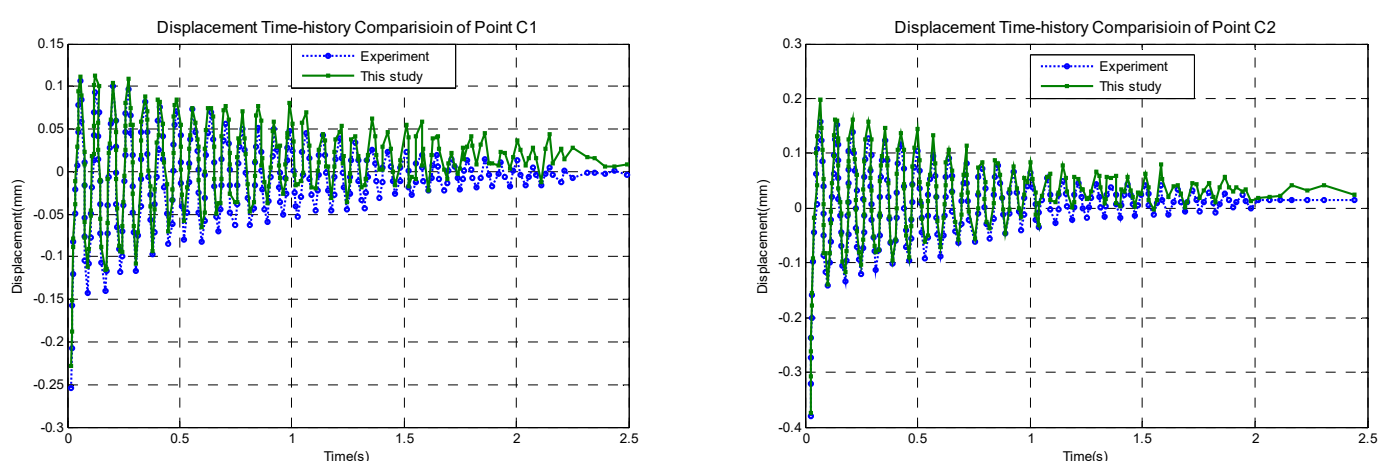

Figure 6. The comparison of the displacement time history of $\mathrm{C} 1$ and $\mathrm{C} 2$.

\section{Numerical Simulations}

\subsection{Simulation Model}

In order to verify the analytical prediction, some numerical investigations were carried out via the commercial software LS-DYNA (incensed by ANSYS 19.0). The prototype model has been developed using a popular steel hemi-cylindrical shell with radius $R=5.0 \mathrm{~m}$, length $L=30 \mathrm{~m}$, and thickness $t=0.01 \mathrm{~m}$. The commonly-used steel of Q235 type has been used in such models with an elastic modulus of $2.1 \times 10^{11} \mathrm{~Pa}$, and a Poison's ratio of 0.23 . To consider the effect of air, it was considered as an elastic fluid with bulk modulus 101,325 Pa. In such a case, the effect of air was assumed as an elastic material. The density of air is $1.225 \mathrm{~kg} / \mathrm{m}^{3}$, viscous coefficient $1.81 \times 10^{-5} \mathrm{~kg} /(\mathrm{ms})$, which means $[56,57]$ the sound speed was $c=287.6$. The model sketch is shown in Figure 7. As for the boundary condition 
of shell, both longitude side were pinned. For the boundary of the air, the elements at the ground position were fixed, while the equation of state (EoS) was set to that of an ideal gas, represented by *EOS_IDEAL_GAS.

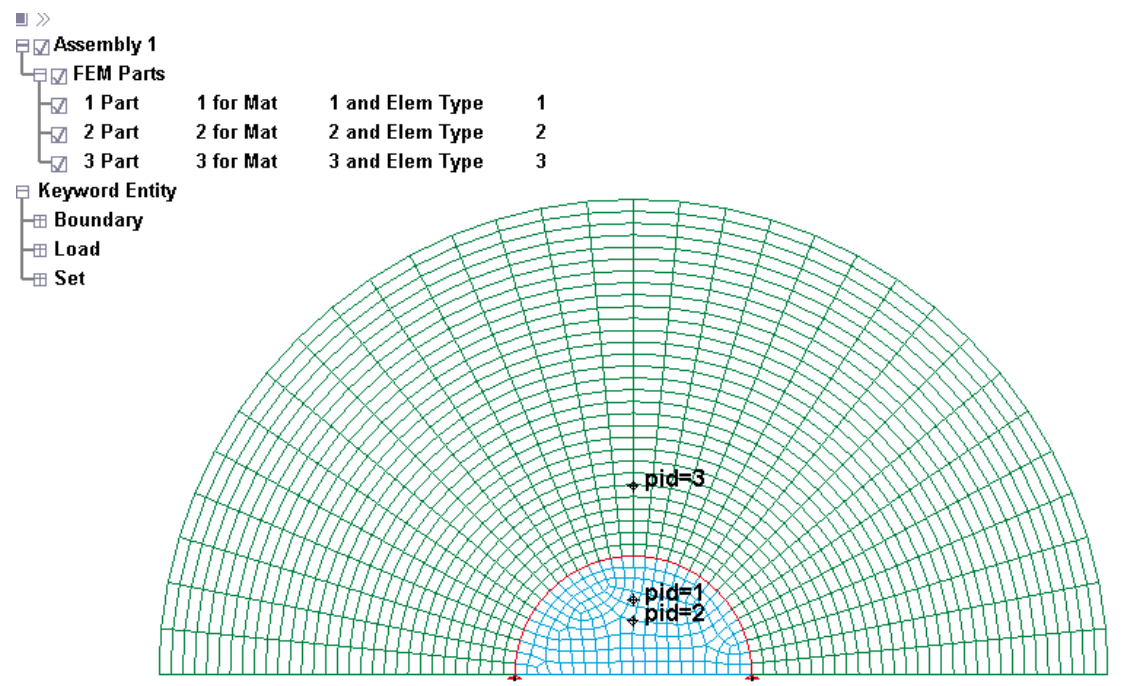

(a)

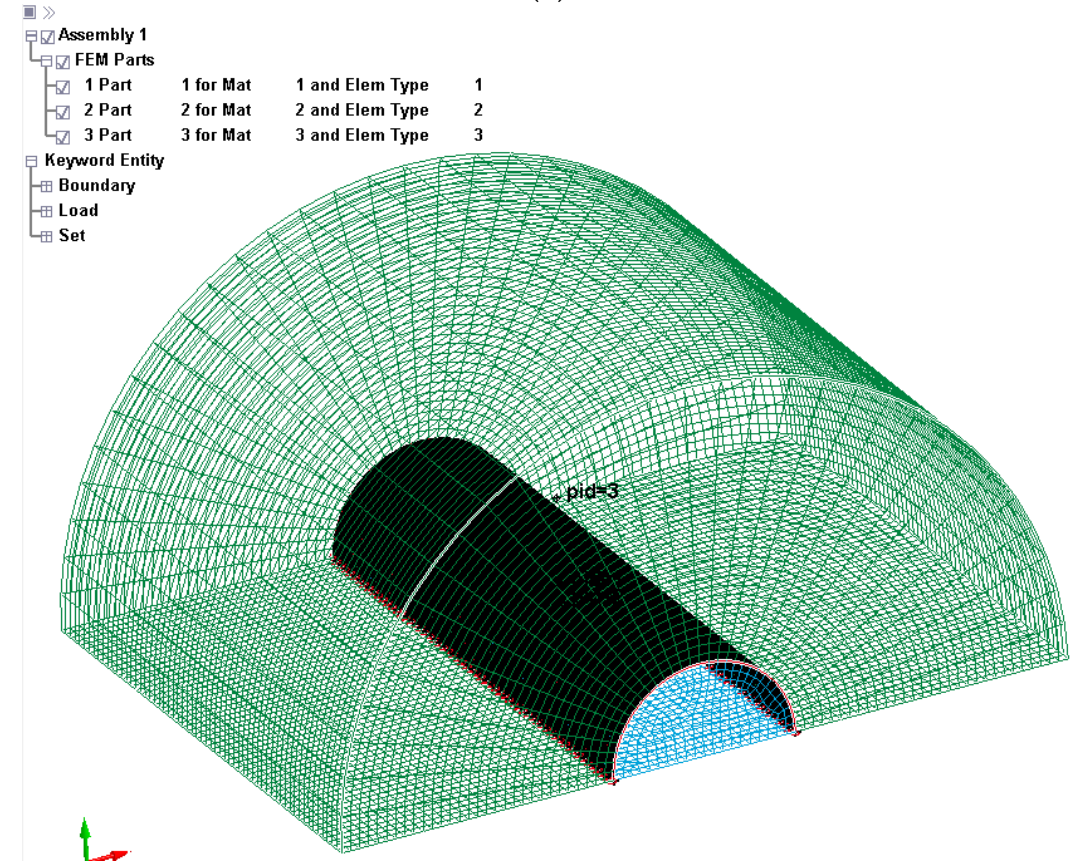

(b)

Figure 7. The sketch of the finite element model. (a) The mesh in the $Z=0$ plane, (b) The mesh of 3-D

As for the parameter analysis, the variable thickness and the ratio of radius to length with a certain blast point are considered. The summary of numerical simulations is list below. The meshing model is presented in Figure 7. And the arrangement of detonation position was present in Figure 8.

Table 1 shows the relationship between total energy, max displacement, and the density of the mesh. Considering the balance of the calculation time and the numerical precision of simulation, the element density of $0.3 \mathrm{~m}$ was accepted in the simulation. After meshing, there were 72,773 nodes, 70,080 elements including 1920 shells, and 68,160 solid elements in the model. The blast point was set to the position of P11, P12, P13, P21, P22, P23, and TNT charge was set to be $10 \mathrm{~kg}$. To save the 
calculation time, the dead time of the blast was set to $0.01 \mathrm{~s}$. As this paper focuses more on energy, the simulation result of the air is not discussed below.

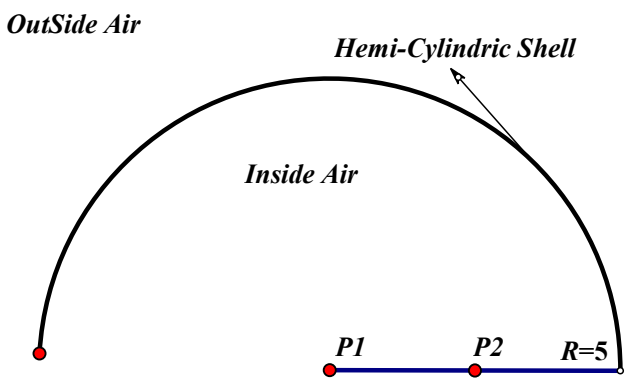

(a)

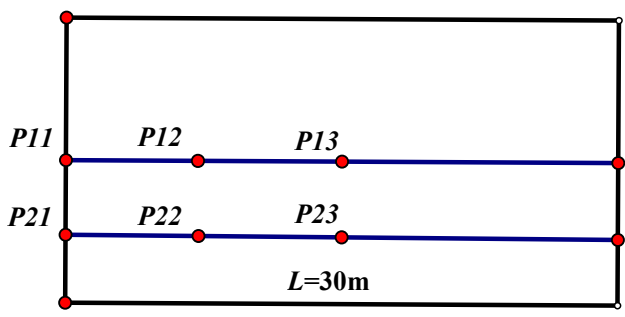

(b)

Figure 8. Model of the vertical view, the plan view and the detonation arrangement. (a) Vertical view. (b) Plan view.

Table 1. The total energy with different density of mesh.

\begin{tabular}{cccccccc}
\hline Density of Mesh $(\mathbf{m})$ & 2.0 & 1.0 & 0.8 & 0.5 & 0.3 & 0.2 & 0.1 \\
\hline Total Energy $\left(\mathbf{1 0}^{\mathbf{4}} \mathbf{~ J )}\right.$ & 4.52 & 4.21 & 3.93 & 3.90 & 3.89 & 3.89 & 3.88 \\
Max Displacement $(\mathbf{m m})$ & 82 & 73 & 70 & 69 & 68 & 67 & 67 \\
\hline
\end{tabular}

\subsection{Natural Frequencies and Corresponding Mode Shapes}

To identify the different vibrational modes in correlation with the position of blast detonation, the modes of vibration and natural frequencies are identified using LS-DYNA. The results are evaluated in this section with a thickness of $0.01 \mathrm{~m}$. Figures 9 and 10 show the edge configuration in the vibrating time $t=0.26 \mathrm{~s}, 0.76 \mathrm{~s}$, and $1.26 \mathrm{~s}$ with the case of P11 and P13, respectively. From both Figures, it can be depicted that the shell vibrates in the symmetrical radial directions.

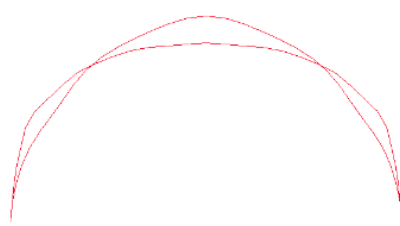

(a)

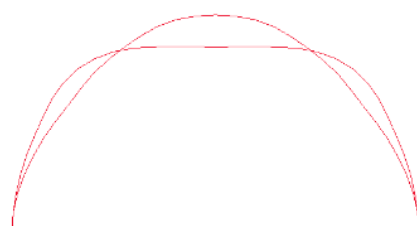

(b)

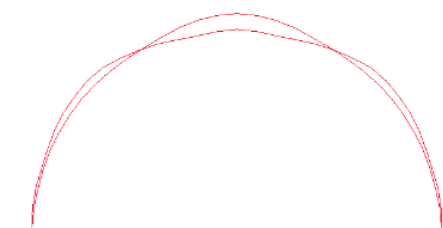

(c)

Figure 9. The displacement mode when $t=0.26 \mathrm{~s}, t=0.76 \mathrm{~s}, t=1.26 \mathrm{~s}, \mathrm{P} 11$. (a) $t=0.26 \mathrm{~s},(\mathbf{b}) t=0.76 \mathrm{~s}$, and $(\mathbf{c}) t=1.26 \mathrm{~s}$.

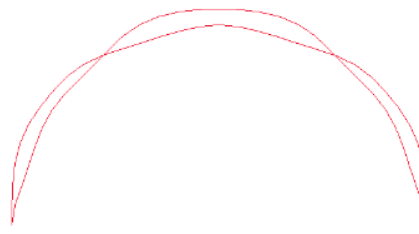

(a)

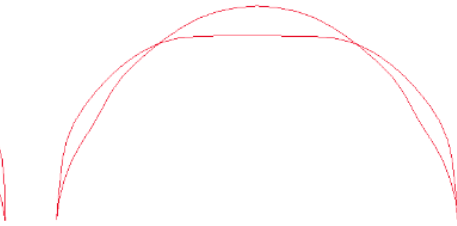

(b)

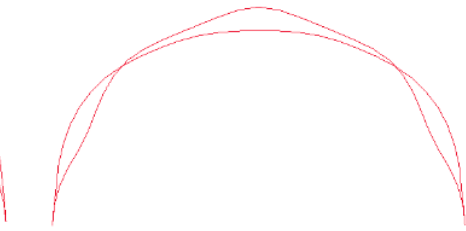

(c)

Figure 10. The displacement mode when $t=0.26 \mathrm{~s}, t=0.76 \mathrm{~s}, t=1.26 \mathrm{~s}, \mathrm{P} 13$. (a) $t=0.26 \mathrm{~s},(\mathbf{b}) t=0.76 \mathrm{~s}$, and (c) $t=1.26 \mathrm{~s}$.

Figure 11a-d show the time history of displacement and correspondent FFT (fast Fourier transformation [58,59]) result. It illustrates that the first three main frequencies are $4.0 \mathrm{~Hz}, 7.5 \mathrm{~Hz}$, and 11.5 HZ excluding the DC component, which means the vibration at the conditions of P11 and P13 comprise of several main frequencies. 


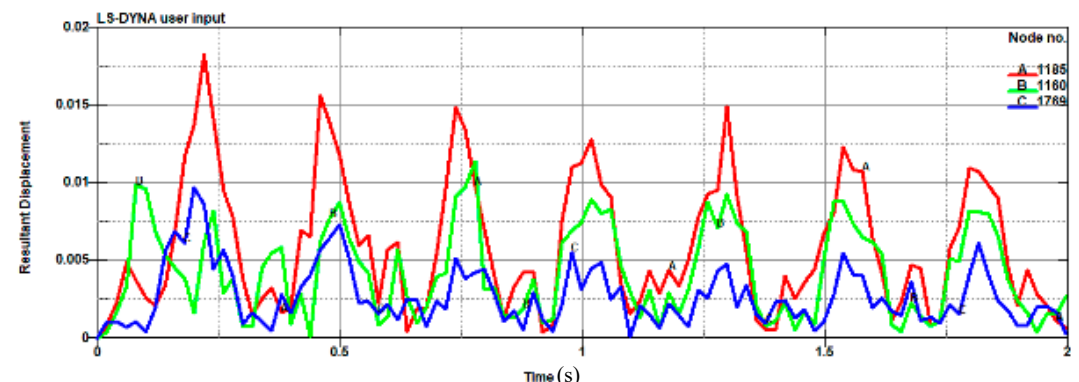

(a)

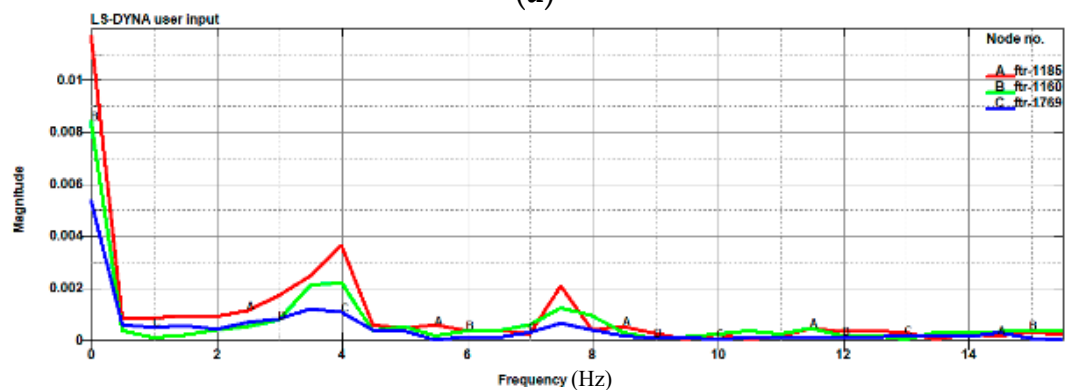

(b)

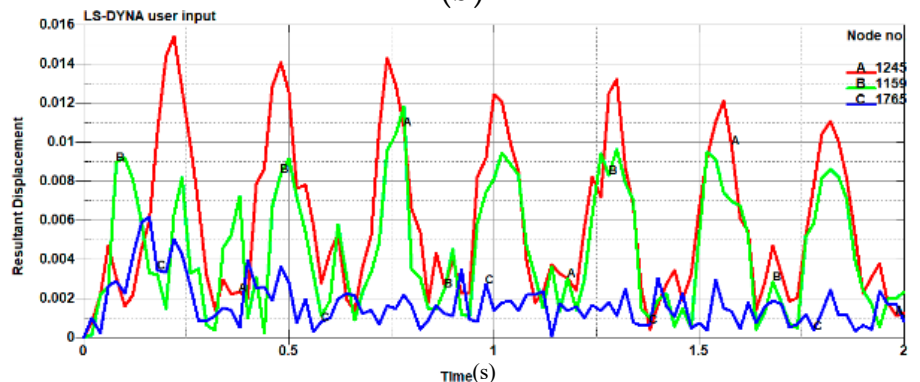

(c)

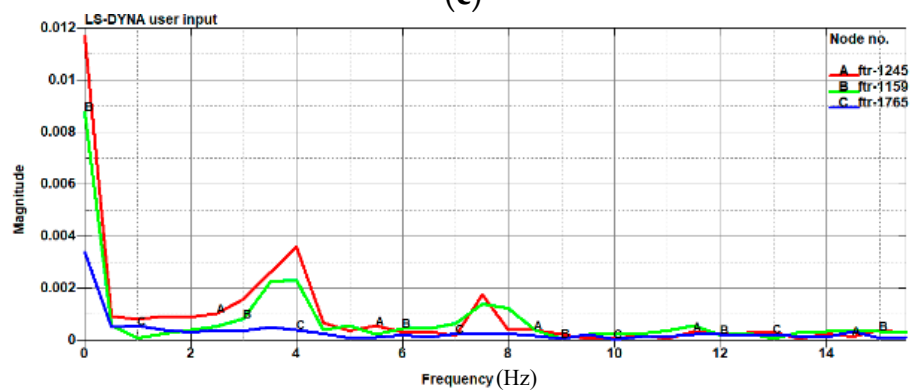

(d)

Figure 11. The displacement vs. time and correspondent result of FFT, P11, and P13. (a) The displacements of points at the condition P11. (b) The corresponding result of FFT at the condition P11. (c) The displacements of points at the condition P13. (d) The corresponding result of FFT at the condition P13.

Figures 12 and 13 show the asymmetrical configuration at the vibrating time $t=0.24 \mathrm{~s}, 0.60 \mathrm{~s}$, and $1.26 \mathrm{~s}$ at the conditions of P21 and P23, respectively. From both figures, it can express that the shell sway left to right and came back periodically.

Figure 14a-d show the time history of displacement and the correspondent result of FFT. It illustrates that the main frequency is $3.5 \mathrm{~Hz}$ excluding the DC component which means the vibration of P11 and P13 has a main frequency. And the main frequency is less than the first order frequency at the conditions of P11 and P13. 


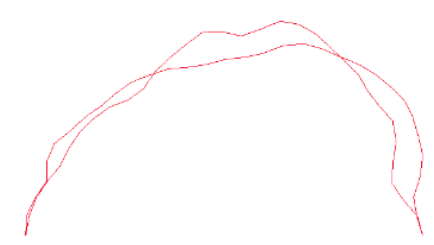

(a)

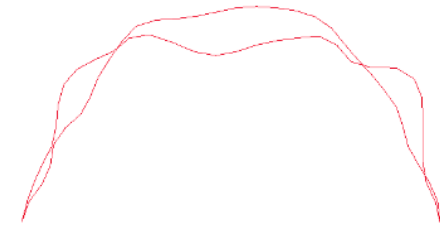

(b)

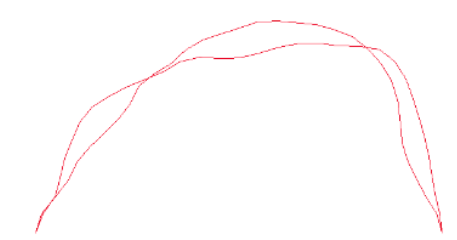

(c)

Figure 12. The displacement mode when $t=0.24 \mathrm{~s}, t=0.60, t=1.26 \mathrm{~s}, \mathrm{P} 21$. (a) $t=0.24 \mathrm{~s},(\mathbf{b}) t=0.60 \mathrm{~s}$, and $(\mathbf{c}) \mathrm{t}=1.26 \mathrm{~s}$.

(a)

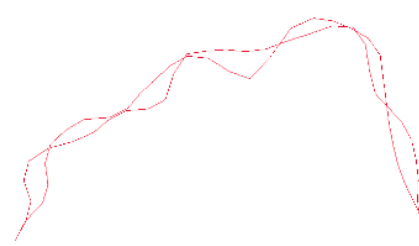

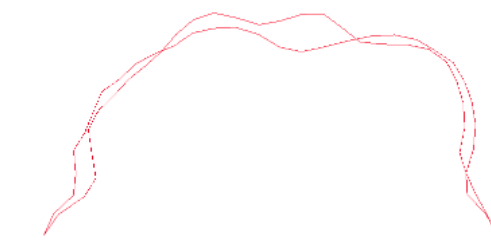

(b)

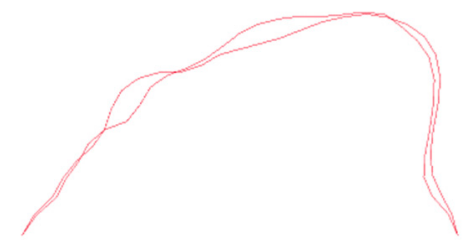

(c)

Figure 13. The displacement mode when $t=0.24 \mathrm{~s}, t=0.60 \mathrm{~s}, t=1.26 \mathrm{~s}$, P23. (a) $t=0.24 \mathrm{~s}$, (b) $t=0.60 \mathrm{~s}$, and (c) $t=1.26 \mathrm{~s}$.

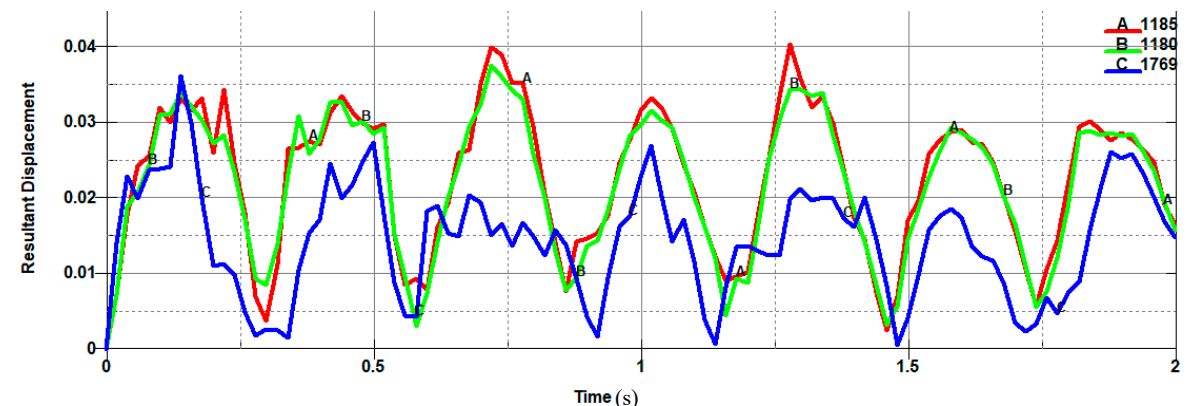

(a)

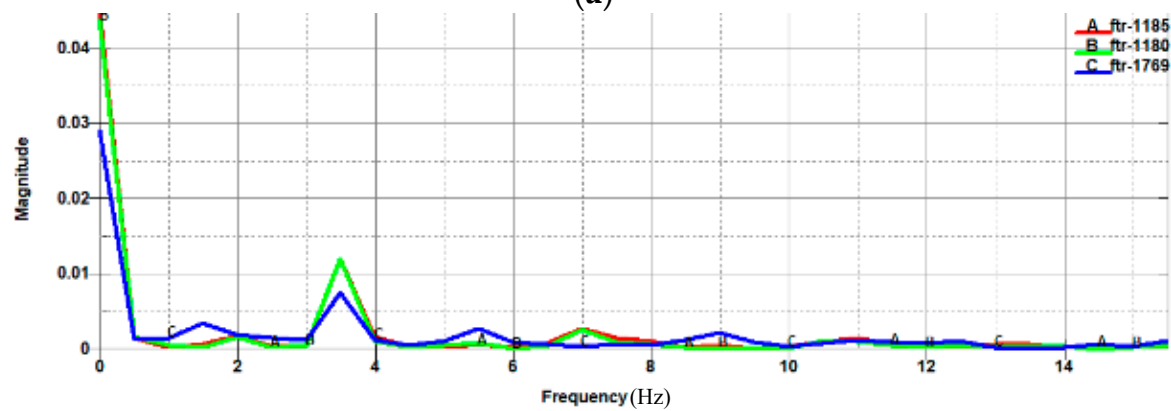

(b)

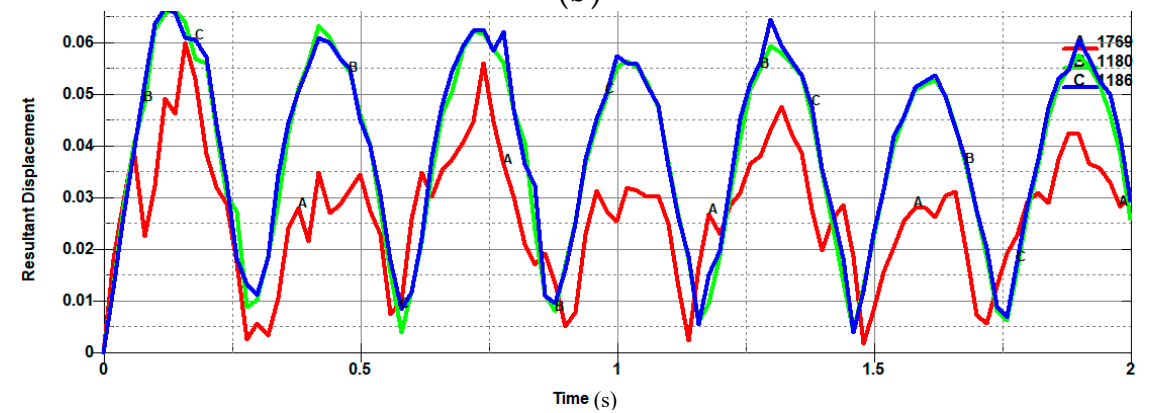

(c)

Figure 14. Cont. 


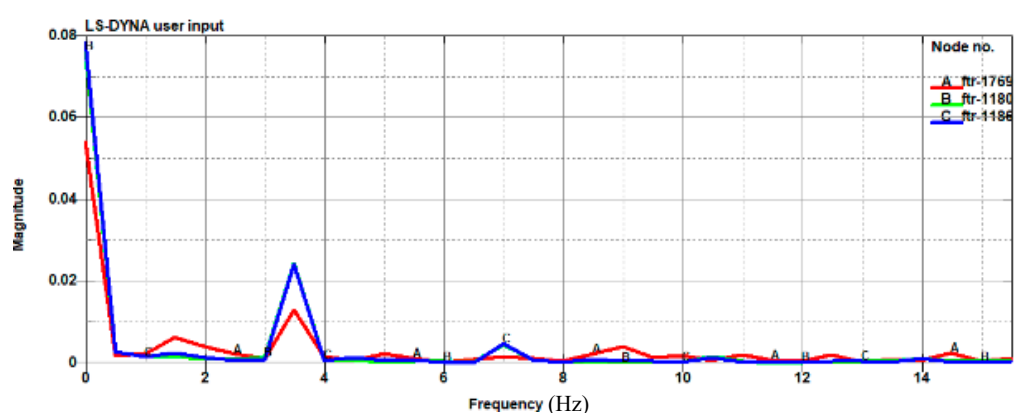

(d)

Figure 14. The displacement vs. time and correspondent result of FFT, P13, and P23. (a) The displacements of points at the condition P21. (b) The corresponding result of FFT at the condition P21. (c) The displacements of points at the condition P23. (d) The corresponding result of FFT at the condition P23.

The different vibrational modes result from different position of blast detonation. Figure 15 depicts the blast load on the condition of P1 and P2. When the detonation is at the middle of the width, blast load acting on the shell are radially uniform as seen in Figure 15, so that the shell is excited only in the radial direction through a localized mode. In contrast, in the asymmetrical condition of blast detonation being at the edge of the structure, the blast load acting on the shell is not symmetrically uniform. The closer the shell element next to the detonation, the larger the asymmetrical blast load is. Therefore, the shell vibrated from left to right in a global mode of vibration.
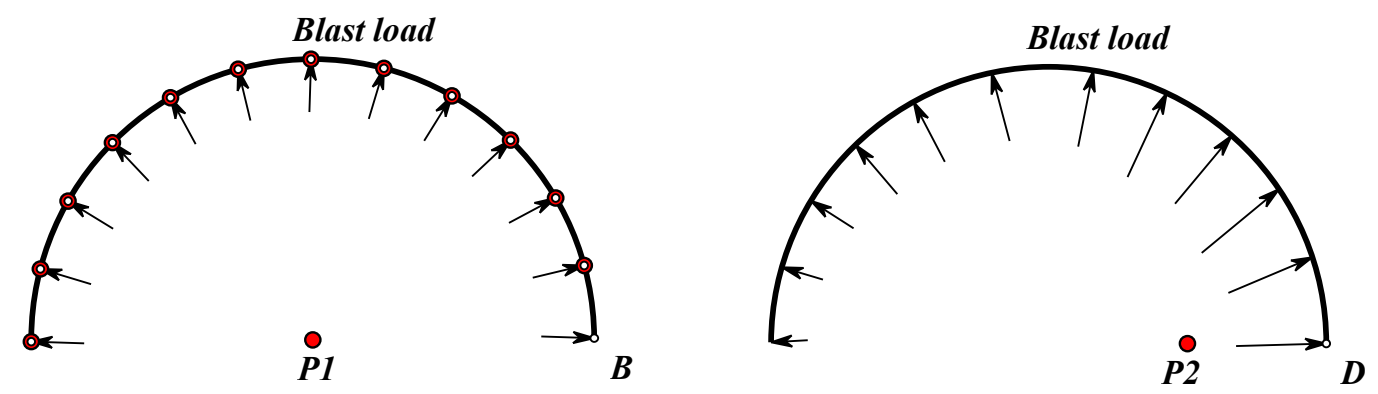

Figure 15. The plot of blast load in the condition of P1 and P2.

\subsection{Global Energy}

The analytical model described above can also calculate the energy responses based on the numerical simulation's parameters. The total energy mainly includes the kinetic energy, the internal energy of the shell, the outside air and the inside air. Figure 16 shows the time history of the global kinetic, internal, and total energy, while Figure 17 plots the time history of the integrations of the kinetic, internal and total energy. From the conservative law of energy, the global total energy should be the same after the blast time $0.01 \mathrm{~s}$. Figure 16 depicts the total energy of all parts is the same after $0.01 \mathrm{~s}$. But the total energy of the shell part alone decreases with respect to time, whereas the internal energy of the air part increases.

Figure 17 shows that the integration of the kinetic energy of the shell part and the internal energy of both the inner air part and outer air part. The result of energy fits Equations (12) and (14) really well. In Equation (14), the formula shows that the total energy decrease with the principle of exponential function. And, the result in the Figures 16 and 17 was in the appliance to such laws. This means that the energy decreased from the shell element is the reciprocal effect as the increase of the energy of the air parts interacting with the shell. Importantly, the increased energy of the inside air and the outside air are almost the same. 

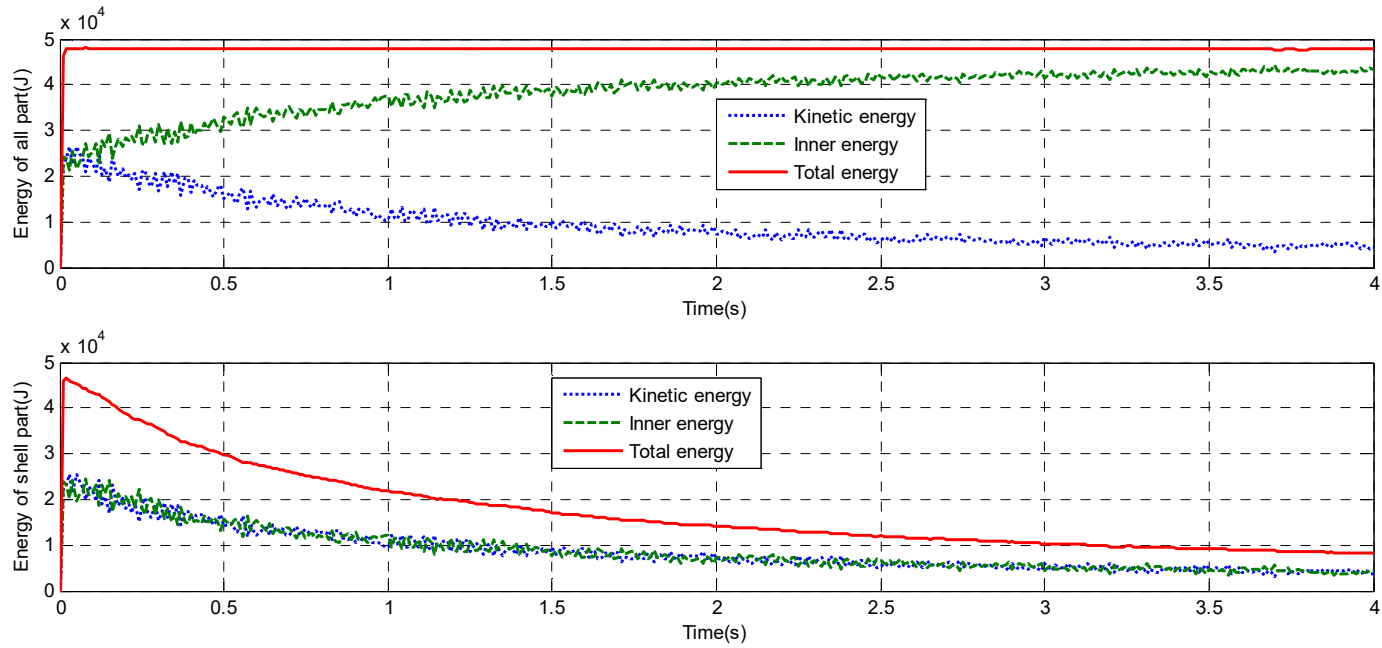

Figure 16. The plot of global and shell part energy vs. time. (a) The energy plot of all parts in the simulation, (b) The energy plot of shell part

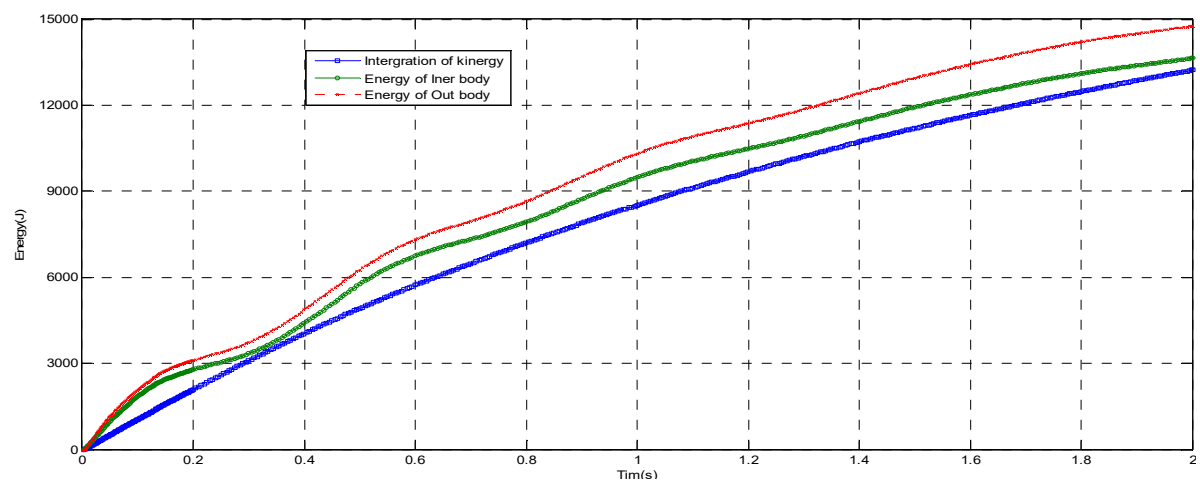

Figure 17. The plot of energy vs. time and the integration of shell part energy.

\subsection{Displacement}

To compare the different displacement modal, the contour map of condition P12 and P22 with varied timed are shown in Figures 18 and 19. Figure 18 illustrates the radial displacement with the times of $0.6 \mathrm{~s}, 1.2 \mathrm{~s}, 1.8 \mathrm{~s}$, and $2.4 \mathrm{~s}$ respectively. It can be concluded that there is no evitable modal displacement in both circumferential and longitudinal directions. Figure 19 also demonstrates that in the circumferential direction, there is evitable displacement, while in the longitudinal direction, the displacement modal is not obvious. 

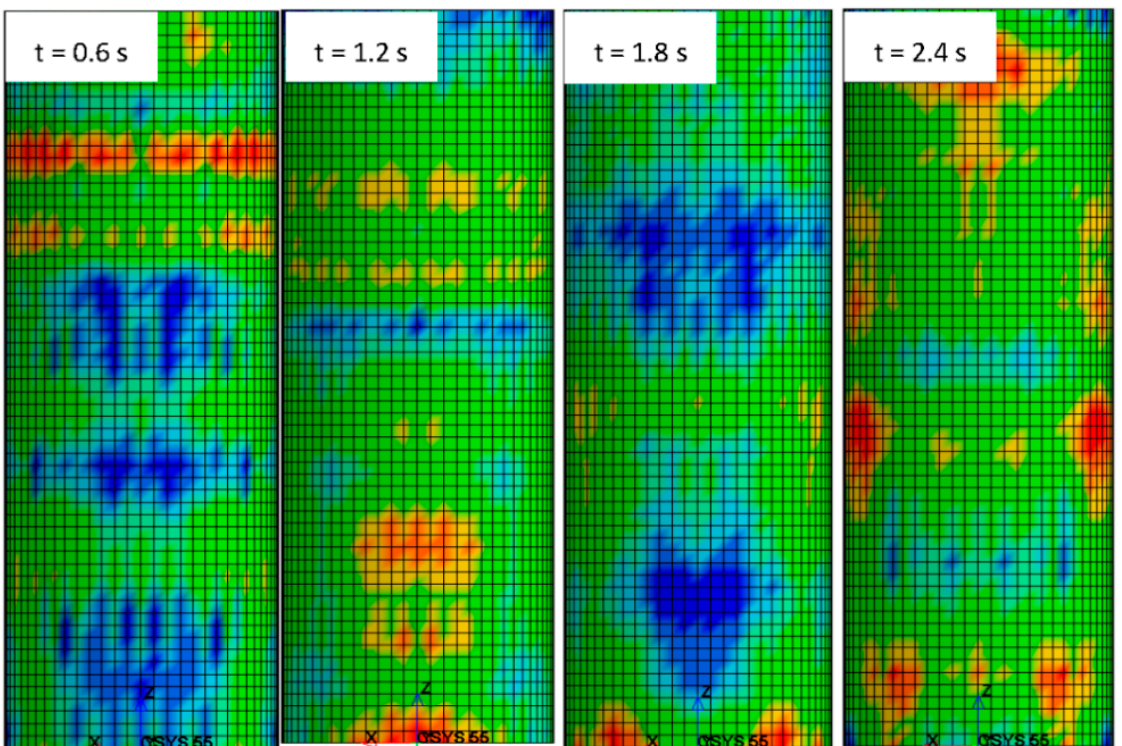

Figure 18. The contour of the radius-displacement when the thickness is $0.01 \mathrm{~m}, \mathrm{P} 12$.
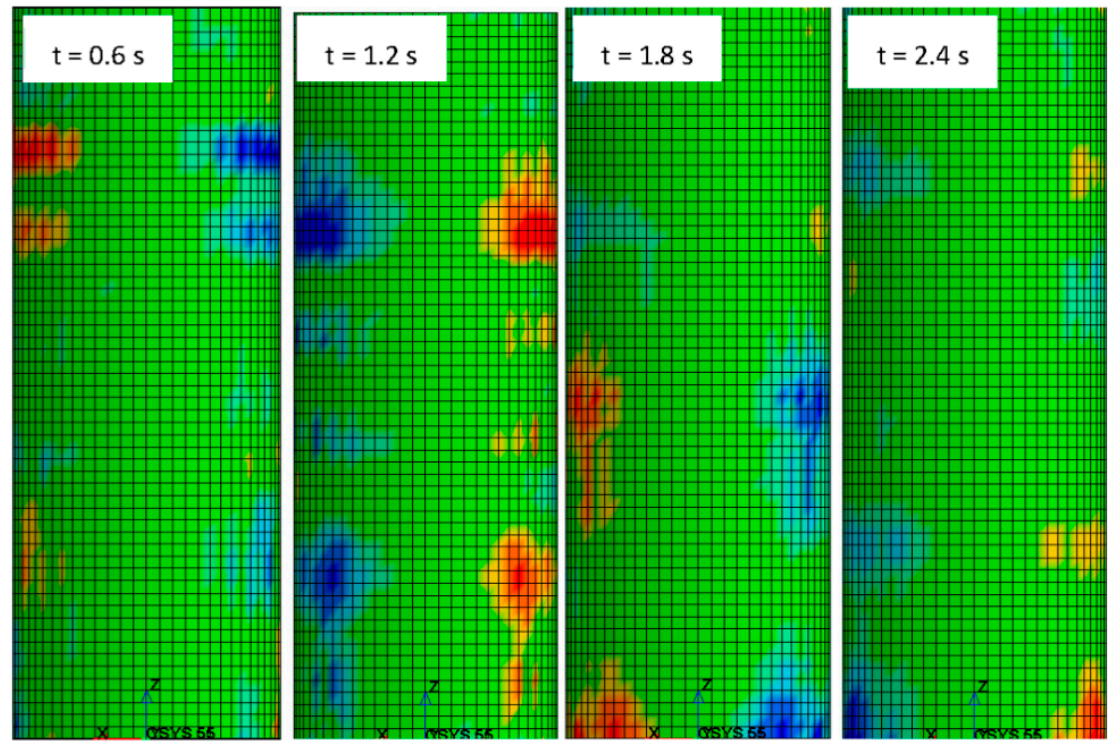

Figure 19. The counter of the radius-displacement when the thickness is $0.01 \mathrm{~m}, \mathrm{P} 22$.

\subsection{The Velocity of the Air Part}

Figure 20 depicts the velocity counter of air part. Figure 20a shows that of air outside and Figure 20b illustrates that of air inside. It can be seen from Figure 20a that the velocity of the radial direction is almost the same in the circumferential direction. That mean the velocity of the shell is same in the radial direction for the velocity of the boundary air is from the motion of the shell. As for the part of air inside, the principle of radial velocity is same except for the larger value.

Figure 21 depicts the velocity contour of the air part at the condition of P22. The Figure 21a shows the contour of the air part outside and Figure 21b illustrates that of the air part inside. It can be seen from Figure 20a, the radial velocity is very different in the circumferential direction, on the other hand, the radial velocities almost are the same according to Figure 20b. The velocity in Figure 21 plots that the air flow from left to right which means that the shell vibrates from left to right. These differences contributed from different vibration modal were discussed in Section 3.3. 


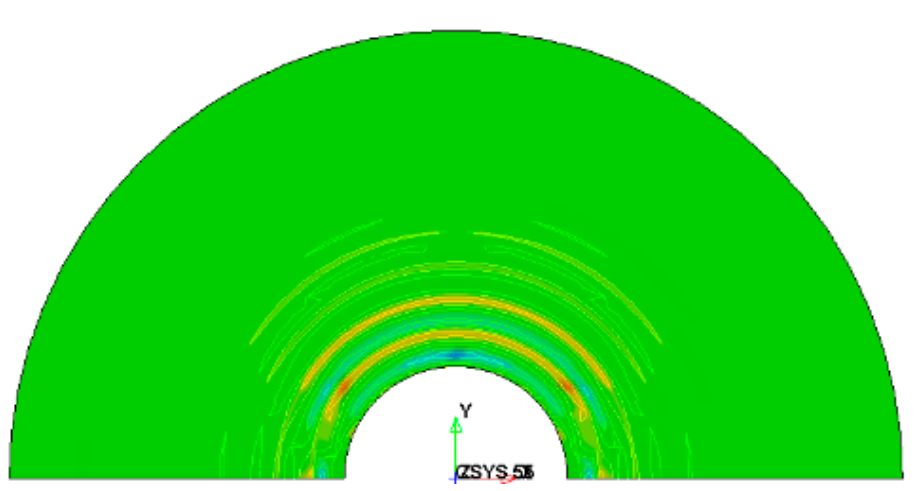

(a)

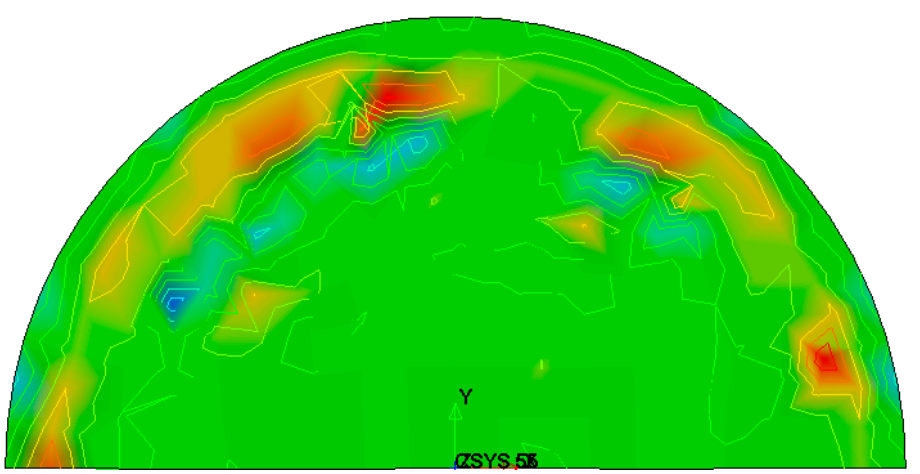

(b)
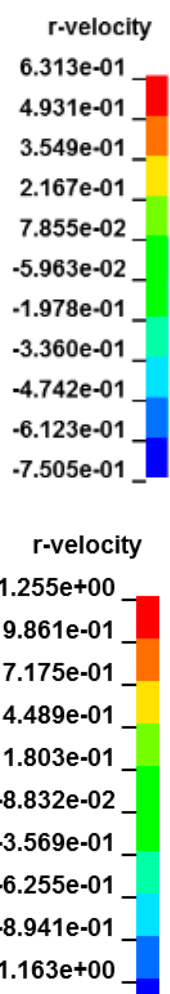

$1.255 \mathrm{e}+00$

9.861e-01

$175 e-01$

4.489e-01

1.803e-01

$-8.832 \mathrm{e}-02$

$-3.569 \mathrm{e}-01$

$-6.255 \mathrm{e}-01$

-8.941e-01

$-1.163 e+00$

Figure 20. The velocity counter of the air part with a thickness of $0.01 \mathrm{~m}, \mathrm{P} 12$, when $t=1.20 \mathrm{~s}$. (a) Air part outside. (b) Air part inside.

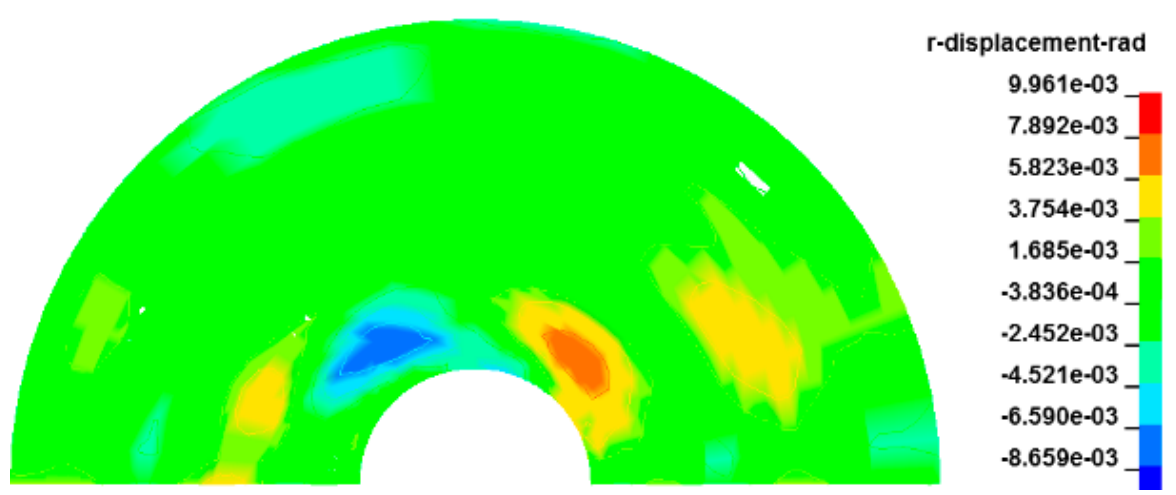

(a)

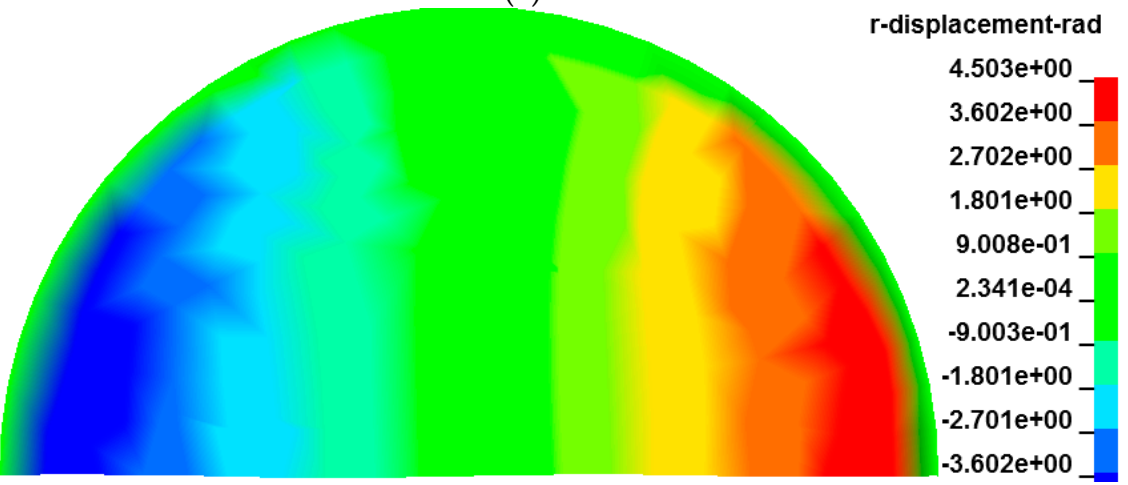

(b)

Figure 21. The velocity counter of air part with thickness $0.01 \mathrm{~m}, \mathrm{P} 22$, when $t=1.20 \mathrm{~s}$. (a) Air part outside. (b) Air part inside. 


\section{Parametric Analyses}

It is apparent that the new analytical model can be used very well to predict the blast effects on the hemi-cylindrical shell structures. However, to enhance the insight into the blast responses of the structure in operations for real world applications, it is crucial to carry out further parametric studies.

\subsection{Displacement Analysis}

Figure 22 shows the displacement time history of three points and the consequent FFT result on the condition of thickness $0.03 \mathrm{~m}, R=5.0 \mathrm{~m}, z=L / 4, x=0.0$. The coordinates of the three points are $(0, R, 0),(0, R, L / 2),(\mathrm{R} / 2, \sqrt{3} / 2 R, L / 2)$, respectively. From Figure 22 , it is very clear that there are several main frequencies and the dominant frequency is large. Thus, according to the discussion above, when the blast detonation position is at the middle of the shell, it can be derived that the energy decrease principle can be described in the formula shown as Equation (14).
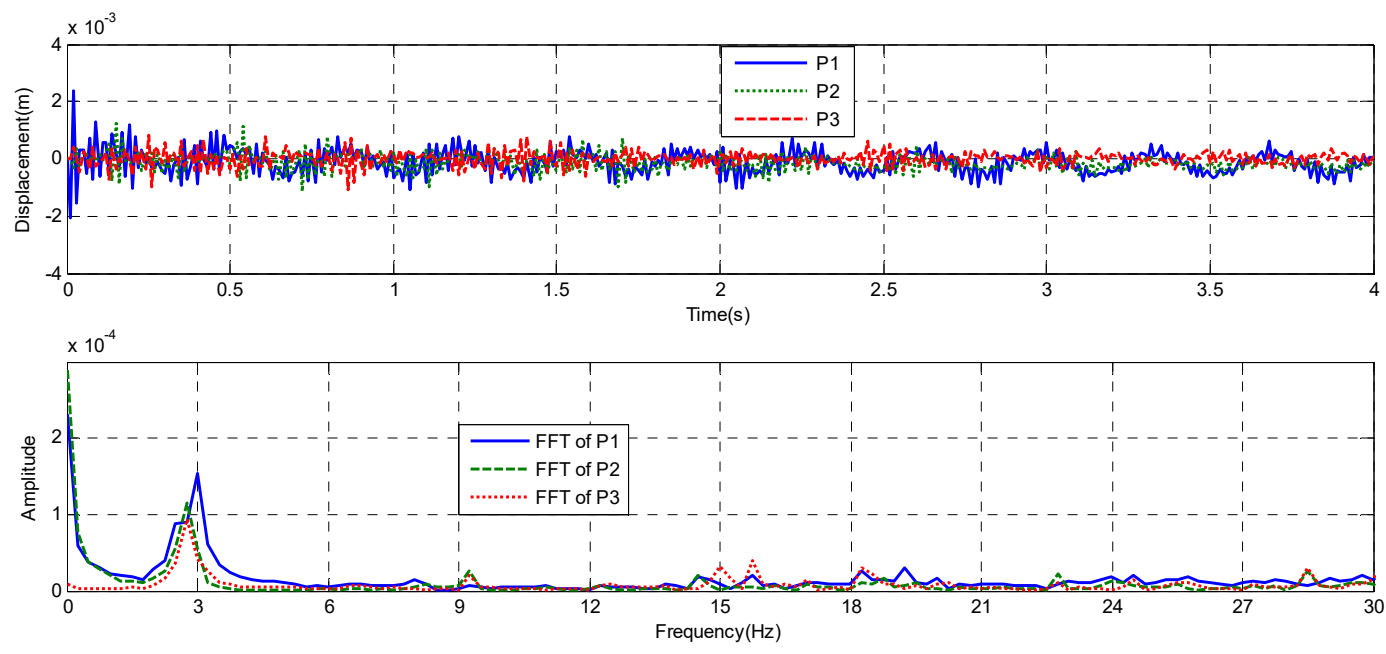

Figure 22. The plot of displacement time history when the thickness is $0.03 \mathrm{~m}, \mathrm{P} 12$.

Figure 23 shows the $x$-displacement time history of the same three points and the consequent FFT with the condition of thickness $0.03 \mathrm{~m}, R=5.0 \mathrm{~m}, z=L / 4, x=R / 2$. The main frequency is $1.3 \mathrm{~Hz}$ which is the dominant one in the whole frequencies. That means when the blast detonation position is close to the edge, the principle can still be described by the formulation of Equation (18).
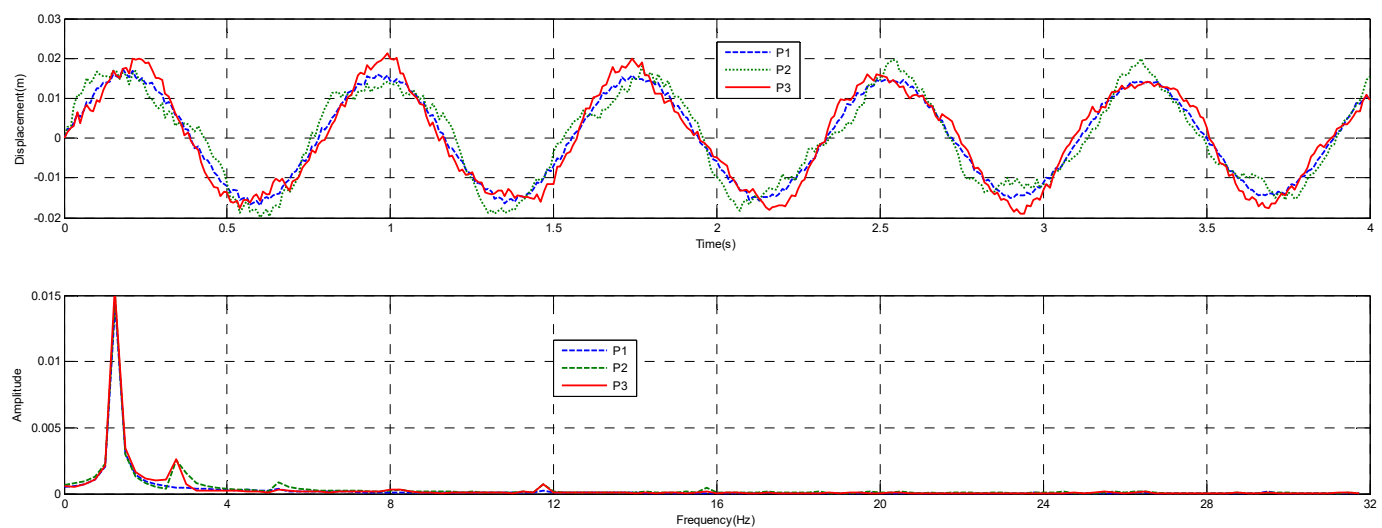

Figure 23. The plot of $\mathrm{x}$-displacement vs. time when the thickness is $0.03 \mathrm{~m}, \mathrm{P} 22$.

Figure 24 presents a configuration after deformation with $x=0$ (P12) and $x=R / 2$ (P22). It shows that, when the detonation is at $x=R / 2$, the configuration modal is in low frequency pattern, while, the 
detonation is at $x=0$, the modal configuration is in large frequency modal. The result of Figure 24 agrees very well with those of Figures 20 and 21. The deviation is less than $4 \%$.

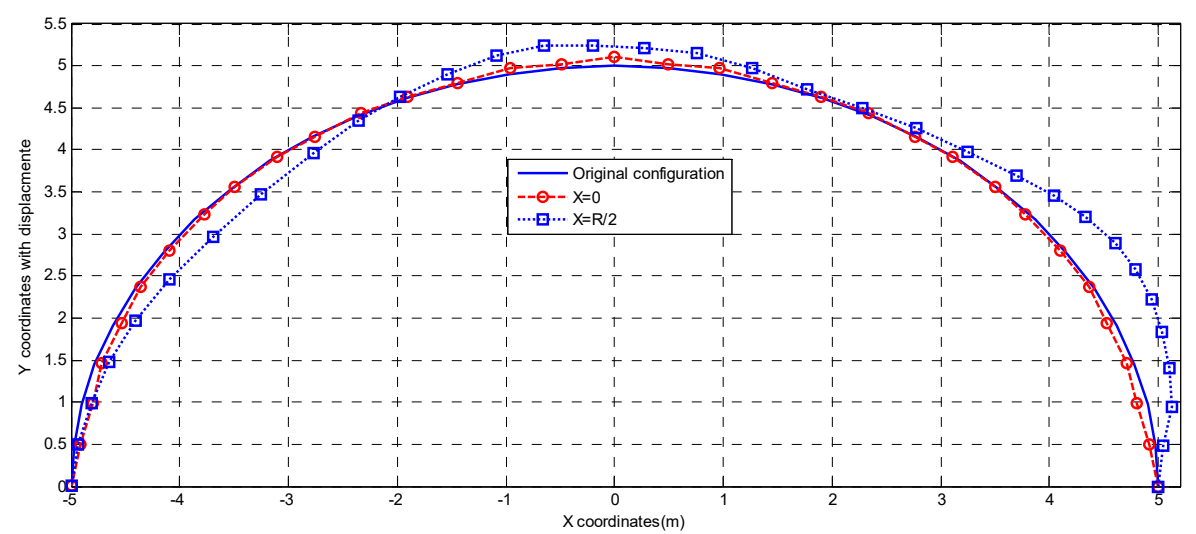

Figure 24. The configuration of the shell with displacement multiplied 50 times, $t=1.30 \mathrm{~s}$.

\subsection{Total Energy vs. Thickness}

To obtain the relationship between $T$ and the decrease ratio $\beta$, some more simulations have been conducted. As mentioned above, $T / D$ should be more than $1 / 100$ and less than $1 / 20$. As the parameter, $D=2 R=10 \mathrm{~m}$, the thickness should be among in $0.01-0.1 \mathrm{~m}$. As predicted in Section 2.1, it can be seen that the value of $\beta$ is proportional inversely to a thickness of $T$, so the typical simulation with the thickness being $0.01,0.015,0.02,0.025,0.03,0.04,0.06,0.10,0.20$, and 0.50 were calculated. The other parameters and results as listed in Table 2. Besides, to compare the different effects of detonation points, the coordinates with $x=0.0, L / 4, L / 2$ are taken accounted in. Detonation point arrangement is listed in Figure 8 above.

Table 2. The initial total energy $\left(\times 10^{4} \mathrm{~J}\right)$ and the ratio $\beta$ at different $T / \mathrm{m}$.

\begin{tabular}{ccccccccccccc}
\hline $\boldsymbol{T}$ & $z / \boldsymbol{L}$ & $\boldsymbol{E}_{\mathbf{0}}$ & $\boldsymbol{\beta}$ & $\boldsymbol{z} / \boldsymbol{L}$ & $\boldsymbol{E}_{\mathbf{0}}$ & $\boldsymbol{\beta}$ & $\boldsymbol{z} / \boldsymbol{L}$ & $\boldsymbol{E}_{\mathbf{0}}$ & $\boldsymbol{\beta}$ & $z / \boldsymbol{L}$ & $\boldsymbol{E}_{\mathbf{0}}$ & $\boldsymbol{\beta}$ \\
\hline 0.010 & & 6.2 & 3.87 & & 12 & 3.74 & & 12.5 & 3.93 & & 9.9 & 3.89 \\
0.015 & & 4.1 & 2.53 & & 8.1 & 2.46 & & 8.25 & 2.59 & & 6.6 & 2.59 \\
0.020 & & 3.2 & 2.03 & & 6.2 & 2.04 & & 6.31 & 2.16 & & 4.9 & 1.94 \\
0.025 & with & 2.5 & 1.44 & $1 / 4$ & 4.8 & 1.72 & $2 / 4$ & 4.94 & 1.89 & $2 / 4$ & 4.0 & 1.55 \\
0.030 & $x=0$ & 2.0 & 0.87 & with & 3.9 & 0.77 & with & 4.03 & 0.83 & with & 3.3 & 1.26 \\
0.040 & $\mathbb{R}=5$ & 1.5 & 0.69 & $R=5$ & 2.9 & 0.65 & $x=0$ & 2.94 & 0.69 & $x=0$ & 2.3 & 0.86 \\
0.060 & $L=30$ & 1.0 & 0.38 & $L=30$ & 2.0 & 0.39 & $L=30$ & 1.96 & 0.38 & $R=7.5$ & 1.5 & 0.33 \\
0.100 & & 0.6 & 0.24 & & 1.2 & 0.24 & & 1.25 & 0.24 & & 1.0 & 0.23 \\
0.200 & & 0.3 & 0.12 & & 0.6 & 0.13 & & 0.59 & 0.12 & & & \\
0.500 & & 0.1 & 0.02 & & 0.2 & 0.03 & & 0.19 & 0.03 & & & \\
\hline
\end{tabular}

From the results of Table 2, the decreasing ratio with radius $R=7.5 \mathrm{~m}$ is the same as that of the radius $R=5 \mathrm{~m}$ at the condition of $Z=2 / 4, X=0$ and $L=30$. Therefore, it can be obtained that the laws about the energy decreasing with time have no effect with the radius of the shell.

Figure 25 shows the fitting curve with data of energy vs. time. The coefficients are listed in Table 2 with $95 \%$ confidence bounds. The fitting curve agrees extreme well with the data seen from the plot. In fact, the other conditions reveal the same outcomes, which are not shown in this paper.

Figure 26 is the plot of the ratio vs. the thickness with $Z=0, L / 4, L / 2$ respectively and $x=0, R=5 \mathrm{~m}$. It can be obtained from the results that the total energy is proportional inversely to the thickness of the 
shell. According to the Equation (4), the moment force can be neglected when the thickness $T$ is small, during the period of the blast, it can be simplified as shown in Equation (20),

$$
\frac{E T}{R^{4}} \frac{n^{2} S^{2}}{\left(n^{2}+\alpha^{2} m^{2}\right)^{2}} \omega+\rho_{s} t \omega^{\prime \prime}=P(t)
$$

where, $P(t)$ is the blast load. According to the Equation (20), the displacement of $\omega$ is proportional inversely to the thickness. The empirical formula can be seen as $E=A / T$, where, $A$ is a parameter depending on the configuration and the materials of the model.

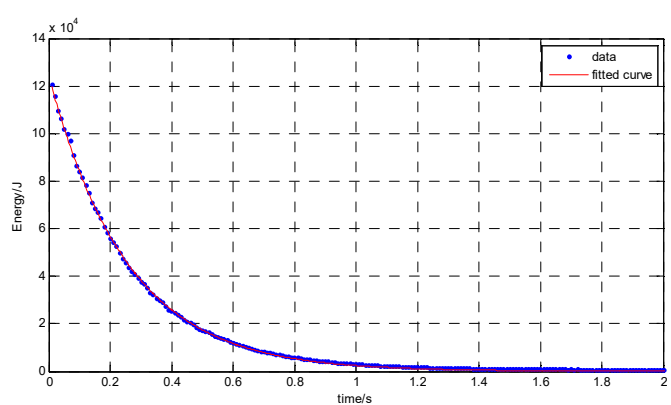

(a)

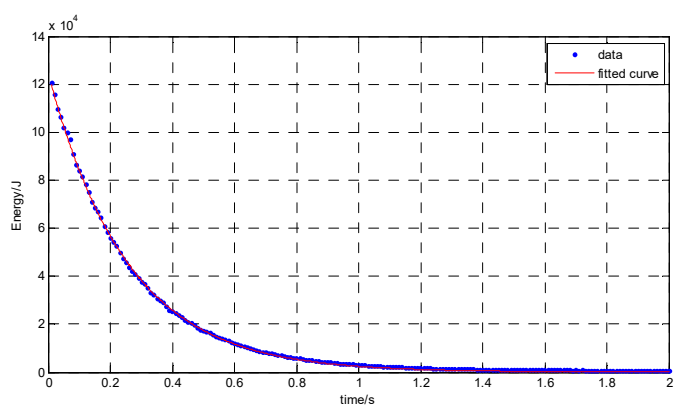

(b)

Figure 25. The energy time history with thickness $t=0.01 \mathrm{~m}, x=0.0 \mathrm{~m}$ and $z=0, z=\mathrm{L} / 2$ respectively. (a) $z=0.0 \mathrm{~m}$. (b) $z=\mathrm{L} / 2 \mathrm{~m}$.

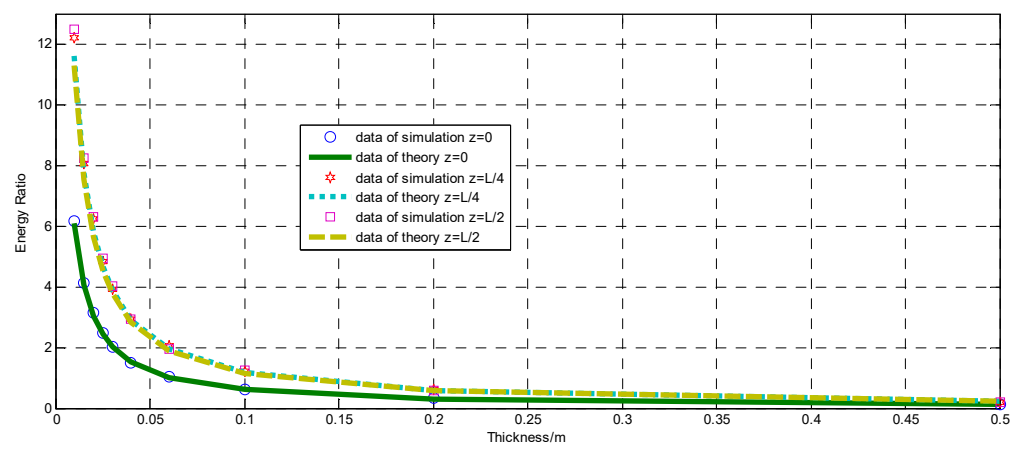

Figure 26. The plot of the ratio vs. thickness when $x=0$.

Figure 27 expresses the difference in the fitting curve and simulation data fitted with Equations (14) and (18), respectively. From Figure 27, it shows that in the conditions of detonation close to the shell side, the decrease of energy agrees with Equation (18) but not Equation (14). And in Equation (18), there are four parameters about $E_{1}, E_{2}, \beta$, and $\alpha$. Where, $E_{1}+E_{2}$ is the total initial energy, $\beta$ is the decrease ratio determined via Equation (12) and $\alpha$ is another decrease ratio determining the difference between internal energy and kinetic energy. All the parameters in different thickness are listed in Table 3 according to the Equation (18).

Figure 28 depicts the principle of total energy $E_{1}+E_{2}$ related to the thickness of the shell. Also, it reveals that the initial energy in the condition of detonation next to shell side also fit the analytical prediction in this study well extremely. 

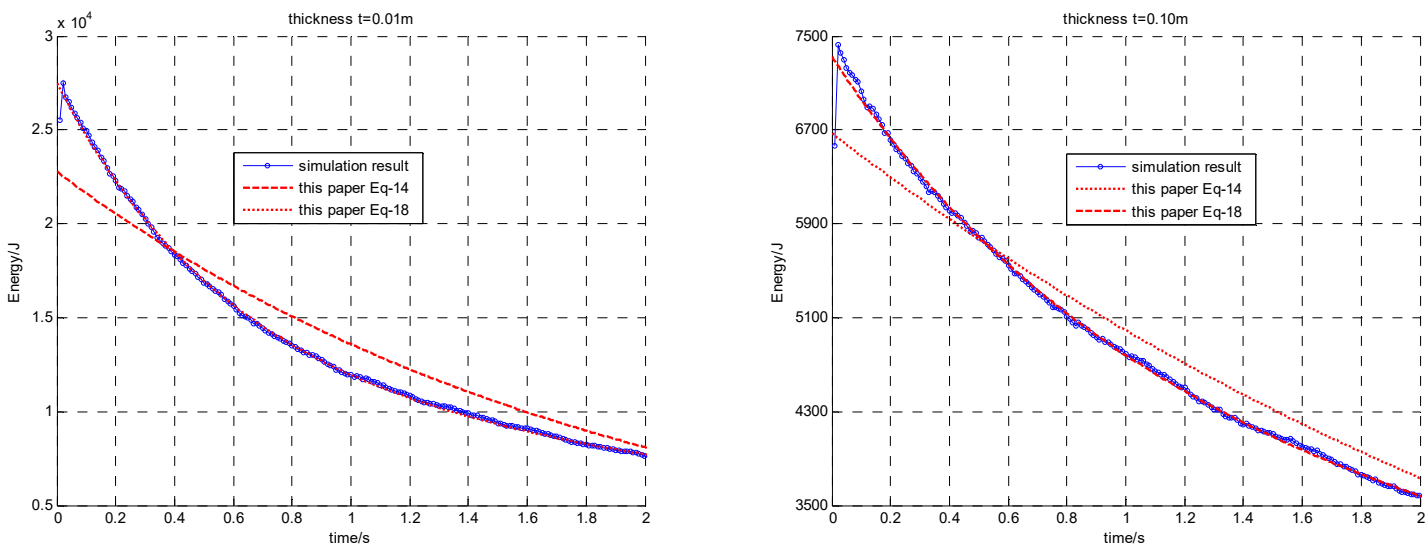

Figure 27. The comparison between Equations (14) and (18).

Table 3. The initial total energy $\left(\times 10^{4} \mathrm{~J}\right)$ and the ratio $\beta$ at different $T / \mathrm{m}$.

\begin{tabular}{cccccccccccccc}
\hline $\boldsymbol{T}$ & $\boldsymbol{z} / \boldsymbol{L}$ & $\boldsymbol{E}_{\mathbf{1}}$ & $\boldsymbol{E}_{\mathbf{2}}$ & $\boldsymbol{\beta}$ & $\boldsymbol{\alpha}$ & $\boldsymbol{z} / \boldsymbol{L}$ & $\boldsymbol{E}_{\mathbf{1}}$ & $\boldsymbol{E}_{\mathbf{2}}$ & $\boldsymbol{\beta}$ & $\boldsymbol{\alpha}$ & $z / L$ & $\boldsymbol{E}_{\mathbf{0}}$ & $\boldsymbol{\beta}$ \\
\hline 0.010 & & 5.2 & 1.6 & 5.12 & 0.38 & & 9.8 & 3.6 & 4.46 & 0.32 & & 9.9 & 3.89 \\
0.015 & & 3.2 & 1.4 & 3.35 & 0.26 & & 5.9 & 3.4 & 3.57 & 0.28 & & 6.6 & 2.59 \\
0.020 & $0 / 4$ & 2.0 & 1.5 & 2.95 & 0.32 & $1 / 4$ & 4.1 & 3.0 & 3.01 & 0.25 & $2 / 4$ & 4.9 & 1.94 \\
0.025 & with & 1.6 & 1.2 & 1.74 & 0.24 & with & 3.1 & 2.5 & 1.81 & 0.24 & with & 4.0 & 1.55 \\
0.030 & $\times 2.5$ & 0.8 & 1.5 & 1.30 & 0.37 & $\times 2.5$ & 2.4 & 2.4 & 1.86 & 0.27 & $\times 0.0$ & 3.3 & 1.26 \\
0.040 & $R=5$ & 0.8 & 0.9 & 1.24 & 0.15 & $R=5$ & 1.6 & 1.9 & 1.41 & 0.17 & $R=7.5$ & 2.3 & 0.86 \\
0.060 & & 0.6 & 0.6 & 1.07 & 0.13 & & 1.3 & 1.1 & 1.18 & 0.13 & & 1.5 & 0.33 \\
0.100 & & 0.3 & 0.5 & 1.11 & 0.17 & & 0.6 & 0.9 & 1.07 & 0.16 & & 1.0 & 0.23 \\
\hline
\end{tabular}

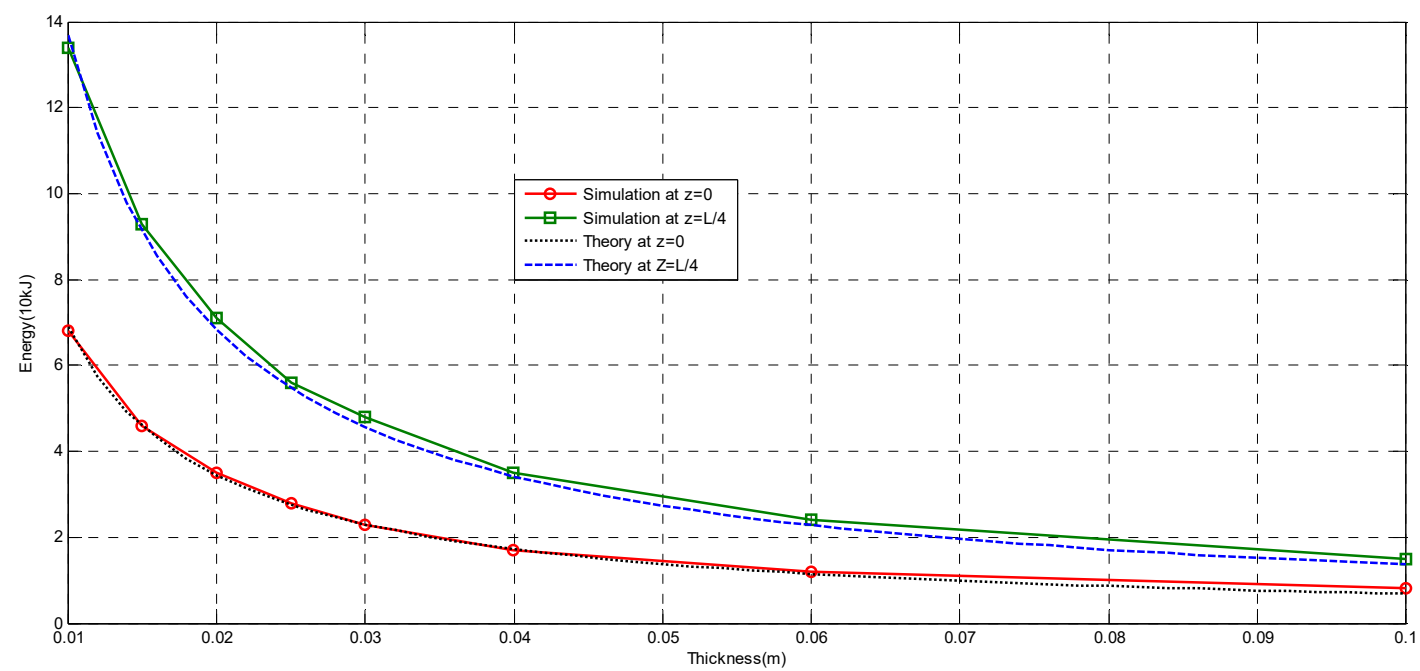

Figure 28. The comparison between Equations (14) and (18).

\subsection{Decrease Ratio vs. Thickness}

As for the parameters described above, it can be known that the sound velocity of air is $c=\sqrt{E_{b} / \rho_{a}}=287 \mathrm{~m} / \mathrm{s}$ resulting in the exponential coefficient being $\beta=\rho_{a} c / \rho_{s} T=0.045 / T$. As predicted from Equation (12), the coefficient is proportional inversely to the thickness of shell. Figure 29 shows the exponential coefficient of energy vs. thickness with $z=0, z=L / 4$ and $z=L / 2$. In addition, the theoretical result above is also illustrated for comparison. The results show that the numerical data fits very well with the analytical prediction. It is also found that the displacement of the shell is proportional inversely to the thickness, resulting in the fact that the energy contributed by damping force is proportional inversely to the thickness as well. 


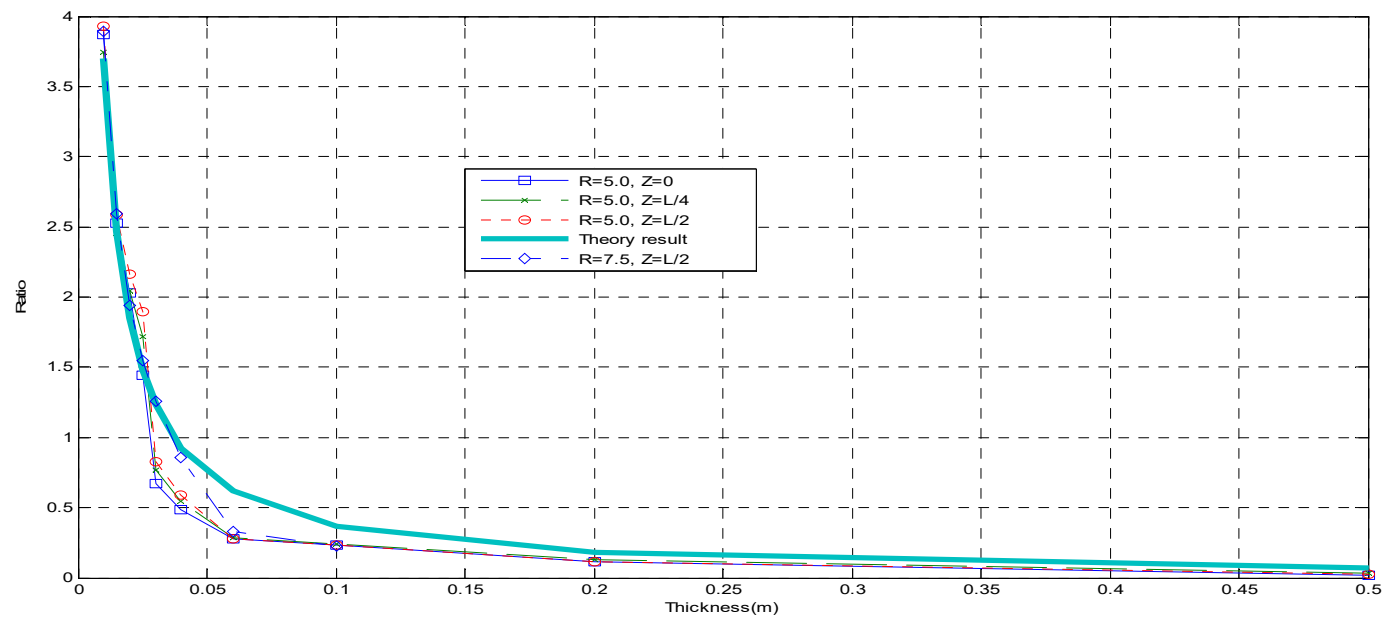

Figure 29. Plot of ratio vs. thickness when $x=0$.

Based on the discussion above, it can be concluded that the energy of shell after blast decreases in accordance with the exponential function, while, the exponential ratio is proportional inversely to the thickness and the scale factor is 2 times of the ratio $\rho_{a} / \rho_{s}$.

Figure 30 illustrates the comparison of the decrease ratio $\beta$ in the conditions of $Z=0, Z=L / 4$, $Z=\mathrm{L} / 2, R=7.5, Z=\mathrm{L} / 2$ and the analytical result, respectively. In the conditions of $Z=0$, the adjusted R-square is 0.89 whilst in the conditions of $Z=L / 4$, the adjusted R-square is 0.94 . In addition, as seen from Figure 30, it can be derived that the analytical and numerical simulation data agree very well in the cases of shell thickness among [0.01 m- $0.06 \mathrm{~m}]$, whilst the discrepancy between simulation and theory becomes larger by a certain degree when the shell thickness is larger than $0.06 \mathrm{~m}$. This discrepancy is because the nature frequency of the shell is very large with the large thickness. In such a case, the assumption of the theory is not exactly correct.

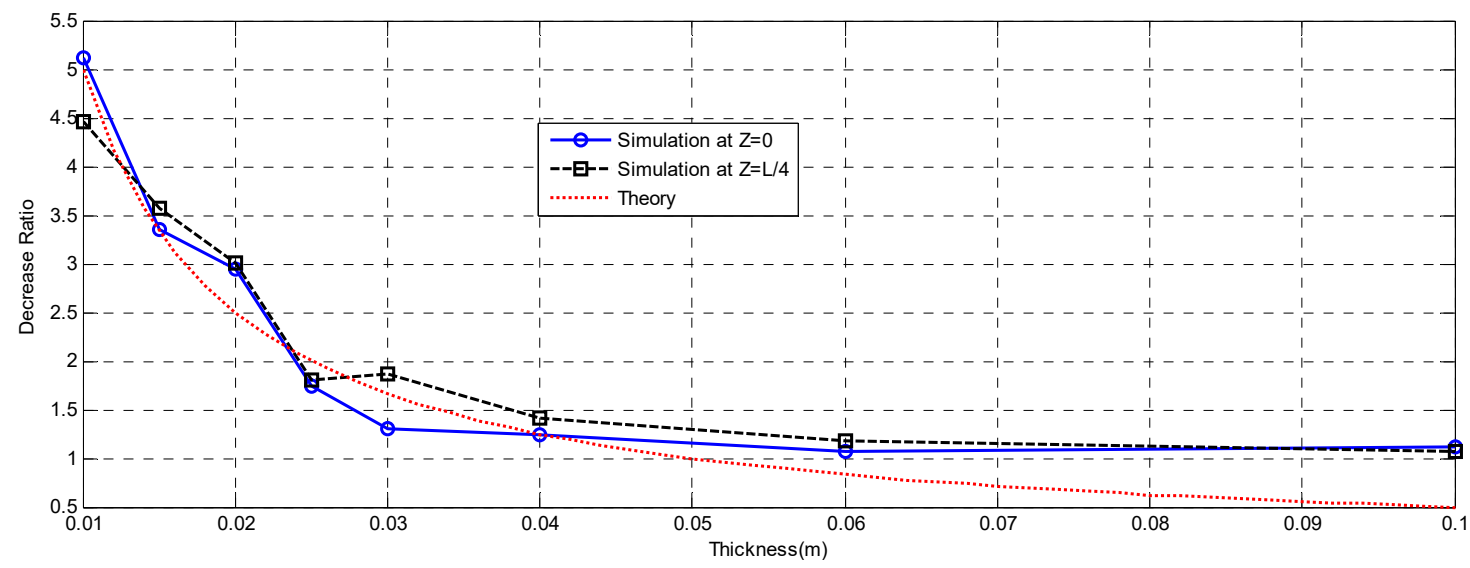

Figure 30. The comparison of decreasing ratio in the conditions of $Z=0, Z=L / 4$ and theory.

\subsection{The Analysis of Elastic Modulus}

The effects of elastic modulus $E$ and Poisson's ratio $v$ have been investigated. Table 4 shows the conditions according to different $E$ and $v$ with $R=5 \mathrm{~m}$ and $L=30 \mathrm{~m}$, where the detonation position is at $(0,0,0),(0,0,0)$, and $(2.5,0,15)$, respectively. 
Table 4. The initial total energy $\left(\times 10^{4} \mathrm{~J}\right)$ and the ratio $\beta$ at different $E$ and $v$, with $R=5, L=30$.

\begin{tabular}{|c|c|c|c|c|c|c|c|c|c|c|c|}
\hline$E$ & $v$ & $E_{0}$ & $\beta$ & $v$ & $E_{0}$ & $\beta$ & $v$ & $E_{1}$ & $\beta$ & $E_{2}$ & $\alpha$ \\
\hline 910 & & 1.89 & 3.29 & & 1.91 & 3.28 & & 3.37 & 3.25 & 5.28 & 0.30 \\
\hline 470 & & 3.46 & 3.45 & & 3.52 & 3.45 & & 2.11 & 5.09 & 3.53 & 0.61 \\
\hline 210 & Case 1 & 6.16 & 3.82 & Case 2 & 5.91 & 3.86 & Case 3 & 10.8 & 6.41 & 3.73 & 0.55 \\
\hline 170 & 0.23 & 6.76 & 4.01 & 0.13 & 7.26 & 3.95 & 0.07 & 12.7 & 7.19 & 3.10 & 0.46 \\
\hline 140 & $Z=0.23 \times 0.0$ & 7.81 & 4.29 & $7=0.10 \times 0.0$ & 8.25 & 4.53 & $Z=2 / 4 \times 25$ & 12.2 & 7.34 & 4.40 & 0.52 \\
\hline 70 & $Z=0 / 4 \times 0.0$ & 10.2 & 4.55 & $Z=0 / 4 \times 0.0$ & 11.7 & 4.62 & $Z=2 / 4 \times 2.3$ & 13.0 & 7.82 & 5.65 & 0.37 \\
\hline 40 & & 11.8 & 4.29 & & 11.7 & 4.42 & & 11.5 & 9.13 & 6.78 & 0.31 \\
\hline 10 & & 14.3 & 4.31 & & 13.8 & 4.37 & & 8.64 & 14.6 & 19.7 & 0.05 \\
\hline
\end{tabular}

Figure 31 presents the curve fitting using an exponential function in accordance with Equation (14). All the analytical results of Case 1 and Case 2 are compliance with the Equation (14). The statistics about the initial energy and decrease ratio can be seen in Table 4 .
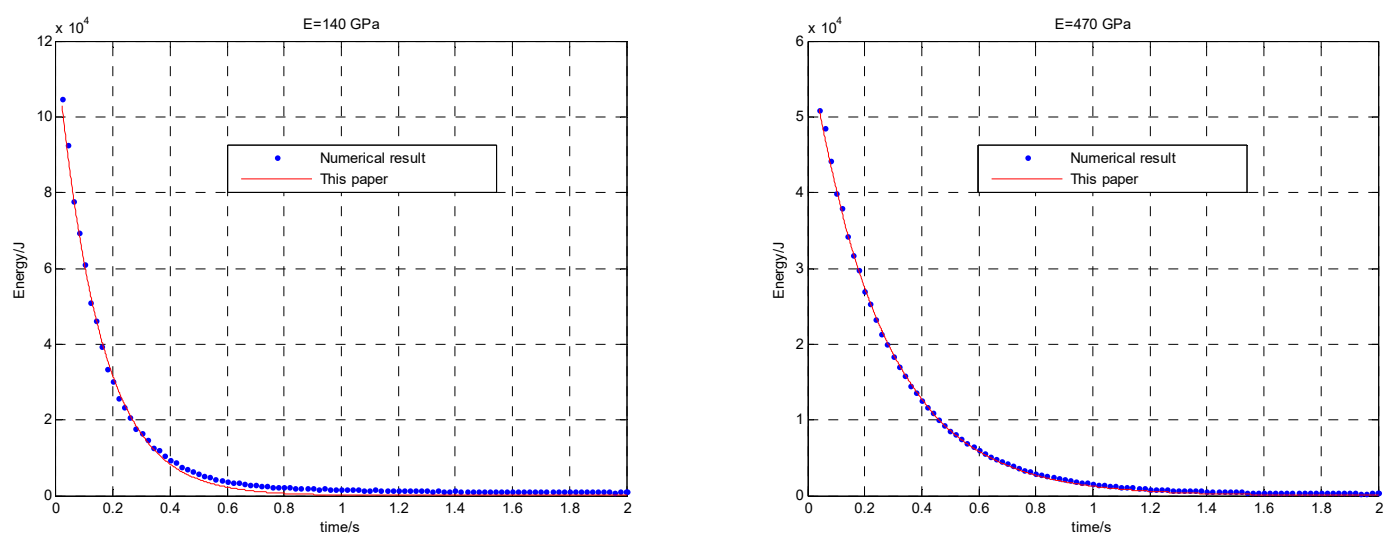

Figure 31. The plot and fitting curve of energy vs. time with $E=140$ and 470 in case 1, respectively.

From the results of Case 1 and Case 2 shown in Figure 32, when only Poisson's ratio changes from 0.23 to 0.13 , it can be seen that the analytical results of both cases are similar, the correlation coefficients of energy and $\beta$ are $0.989,0.989$, respectively. It is evident that the Poisson's ratio has little effect on the initial energy and decrease ratio.
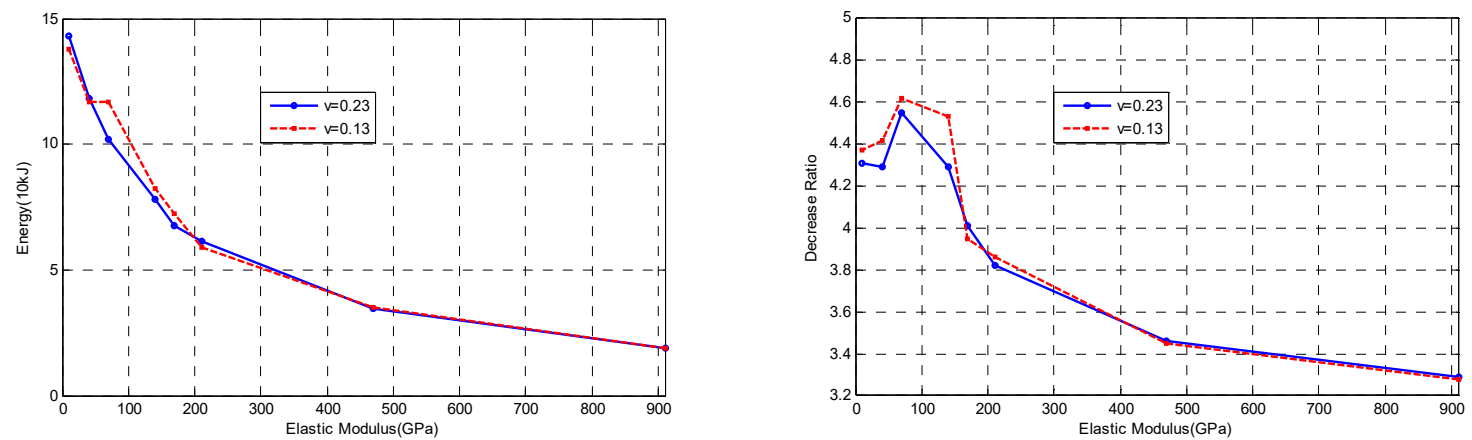

Figure 32. The comparison of energy and decrease ration vs. elastic modulus.

Figure 33 presents the curve fitting using an exponential function in accordance with Equation (18). The correlation coefficients of the two cases is 0.978 and 0.987 , respectively. All the results of Case 3 are in compliance with the Equation (18). The statistics about the initial energy and decrease ratio are shown in Table 4 as well. 

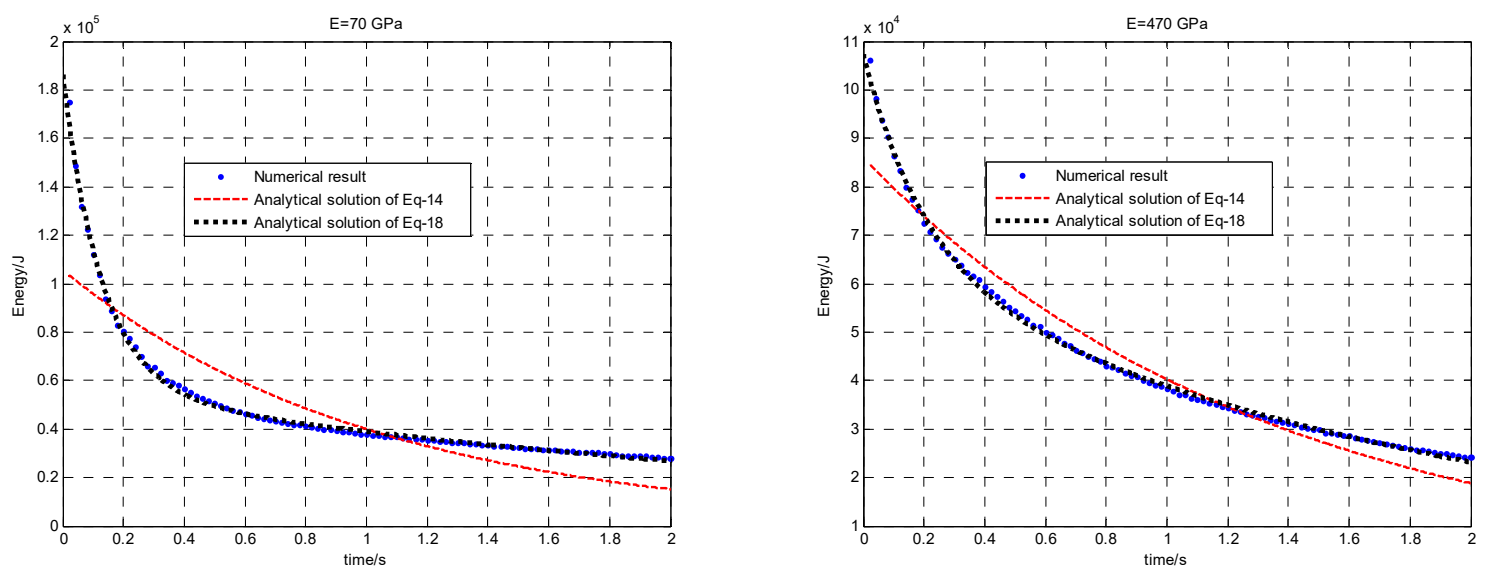

Figure 33. The plot of energy vs. time with $E=70,470$ GPa in case 1, respectively.

Figure 34 illustrates the relationship between initial energy vs. elastic modulus. According to Figure 34, the fitting solutions by the least square method can be obtained. The fitting type is considered as $a /(a+E)$, where $a$ is the parameter which should be determined. The fitting results are in very good agreement with SSE of 0.08 and R-square of 0.9993 , which shows that there can be a rational correlation between energy and elastic modulus. It is noted that, when the elastic modulus limits to zero, the energy tends to be a limited value, not infinite value. That is the influence partially contributed by the air around the shell inside and outside.

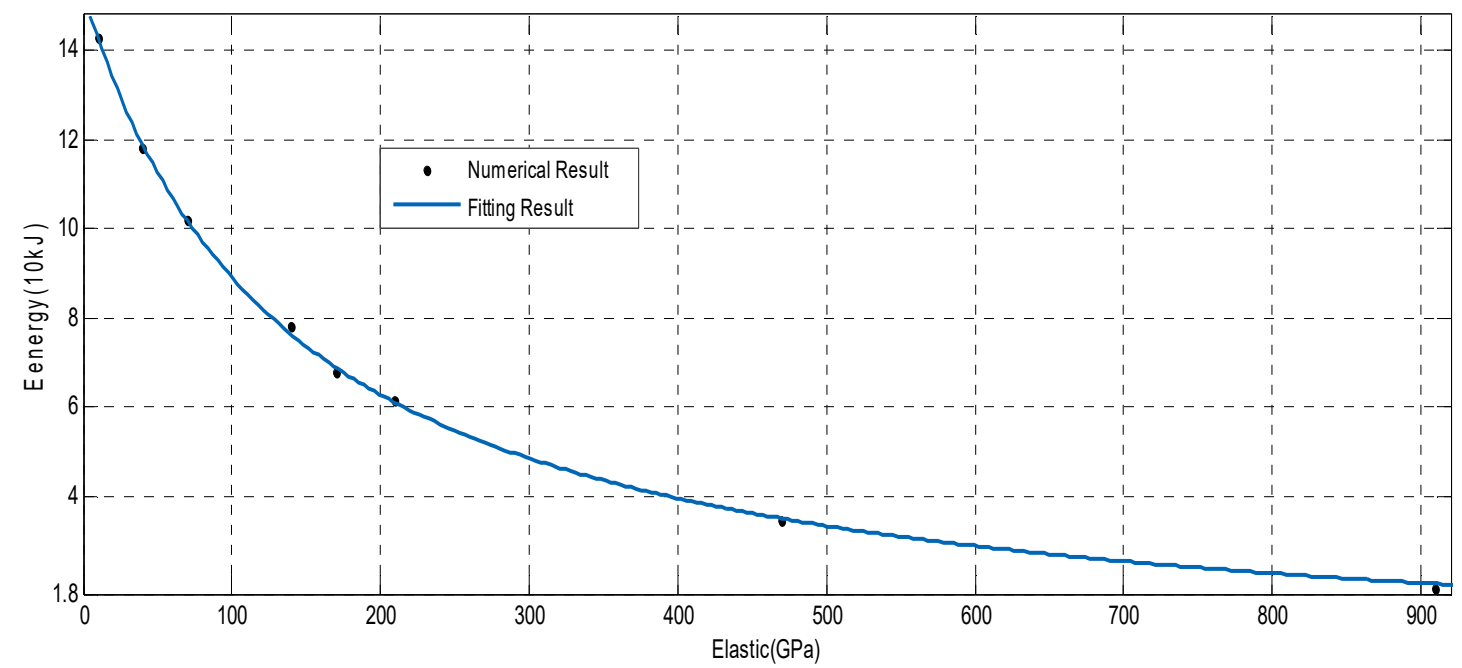

Figure 34. The plot of energy vs. elastic modulus with $t=0.01 \mathrm{~m}$, detonation position, $x=0, z=0$.

\subsection{Material Parameters}

As mentioned in Equations (14) and (18) above, the laws of energy decrease have nothing to do with the different material model. In this section, the simulations at the different material model and different densities have been carried out. Table 5 shows the simulation results in the plastic model of $E=210 \mathrm{GPa}, v=0.23, f_{y}=410 \mathrm{MPa}, E_{t}=4.0 \mathrm{GPa}$ with density being 10, 7.8, 4.0, 2.0, 1.0, 0.6, and $0.3 \mathrm{ton} / \mathrm{m}^{3}$, respectively. Where, $f_{y}$ denote the yield stress, $E_{t}$ tangent elastic modules. In the LS-DYNA software [54,60], the Keywords *MAT_PLASTIC_KINEMATIC was used. It should be noted that in all the situations listed in Table 5, the shell remained in the elastic stage. 
Table 5. Simulation results at plastic kinematic model.

\begin{tabular}{cccccccc}
\hline $\boldsymbol{\rho}\left(\right.$ ton $\left./ \mathbf{m}^{\mathbf{3}}\right)$ & 10 & 7.8 & 4.0 & 2.0 & 1.0 & 0.6 & 0.3 \\
\hline $\boldsymbol{E}_{\mathbf{0}}\left(\mathbf{1 0}^{\mathbf{4}} \mathrm{J}\right)$ & 1.94 & 2.13 & 2.31 & 2.31 & 2.18 & 1.95 & 1.80 \\
$\boldsymbol{\beta}$ & 4.62 & 3.84 & 2.18 & 1.16 & 1.73 & 2.33 & 3.53 \\
\hline
\end{tabular}

From Table 5, it can be found that the density of shell has no obvious relationship with the total initial energy. It still can be found that at the same blast load, the inertial force will decrease with the decrease of density, resulting in an increase of displacement as well. Therefore, the internal energy of the shell after the blast process will increase as well. Meanwhile, the kinetic energy will decrease with the decrease in density. So, the total energy has no significant affection for the changes in density.

Figure 35 shows the relationship of energy vs. time at the condition of density $10 \mathrm{ton} / \mathrm{m}^{3}$. It can be seen that the result fits very well with Equation (14) of this study. Actually, all the other conditions listed in Table 5 fits Equation (14) well.

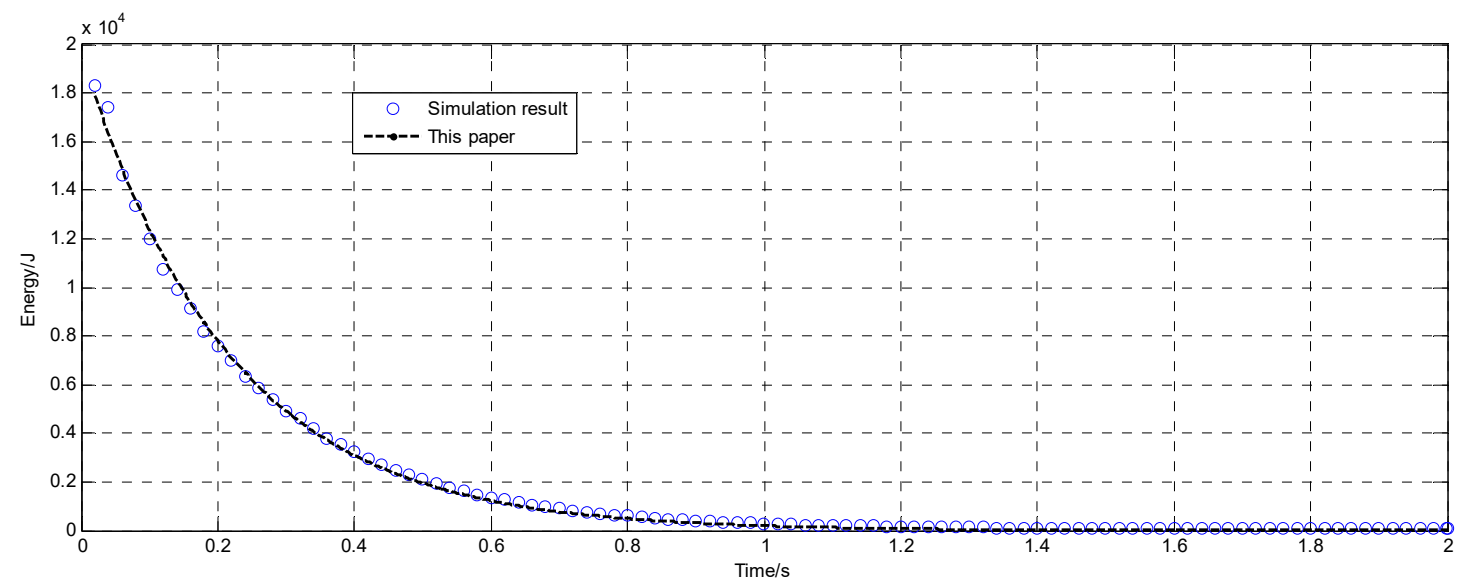

Figure 35. The plot of energy vs. time at density $\rho=10$ ton $/ \mathrm{m}^{3}$.

Figure 36 shows the relationship between the decrease ratio and the density of the shell. From Figure 36, it can be concluded that when the density is less than $2.0 \mathrm{ton} / \mathrm{m}^{3}$, there is an obvious discrepancy between the numerical simulation result and the analytical prediction. Whilst, the density is more than $2.0 \mathrm{ton} / \mathrm{m}^{3}$, the theory result agrees with the simulation result very well. The transit point is at density of $2.0 \mathrm{ton} / \mathrm{m}^{3}$. The results show that the application of Equation (14) is limited in the range of density larger than $2.0 \mathrm{ton} / \mathrm{m}^{3}$. Those characteristics due to the limit of assumption accepted in this study.

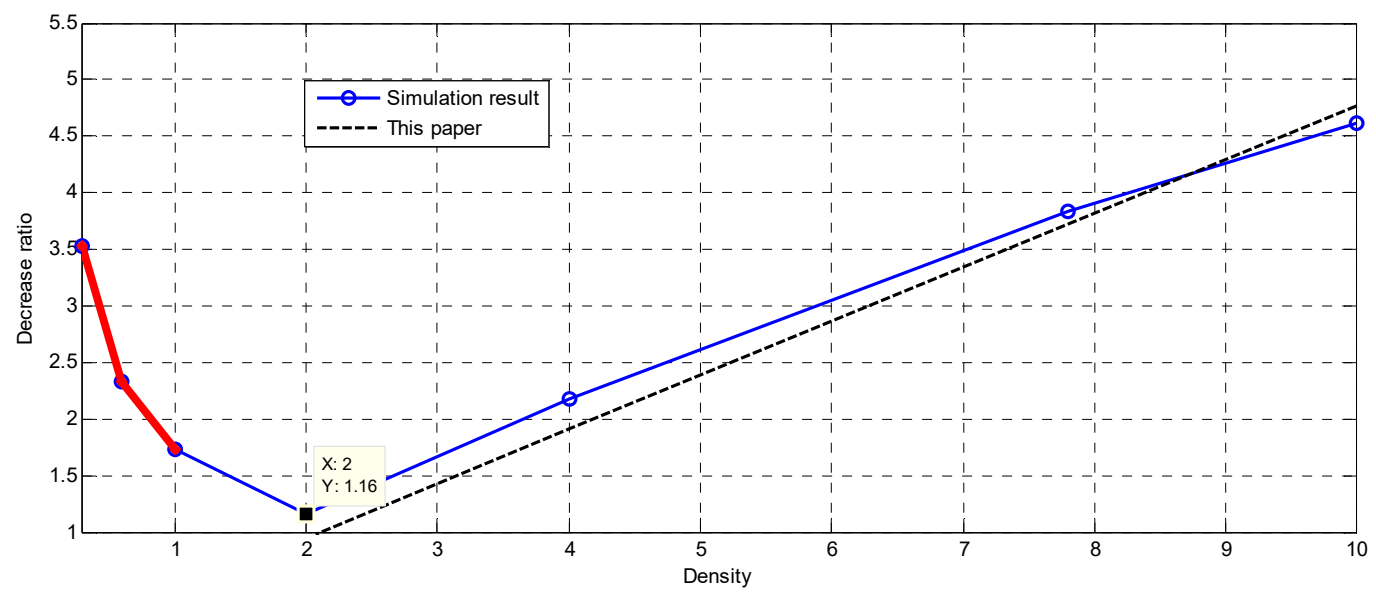

Figure 36. The plot of decrease ratio vs. density $\left(\mathrm{t} / \mathrm{m}^{3}\right)$. 
It should be noticed that on this condition, some shell element goes into the plastic stage. So, the value of $E_{0}$ at conditions of density 4.0,2.0, and $1.0 \mathrm{ton} / \mathrm{m}^{3}$ in Table 5 is the total initial energy, which is also the same as the value of $E_{1}+E_{2}$.

Figure 37 shows that at the condition of density $=2.0 \mathrm{ton} / \mathrm{m}^{3}$, the principle of energy decrease is compliance with Equation (18), while at the condition of density $7.8 \mathrm{ton} / \mathrm{m}^{3}$, the principle of that is compliance with Equation (14).
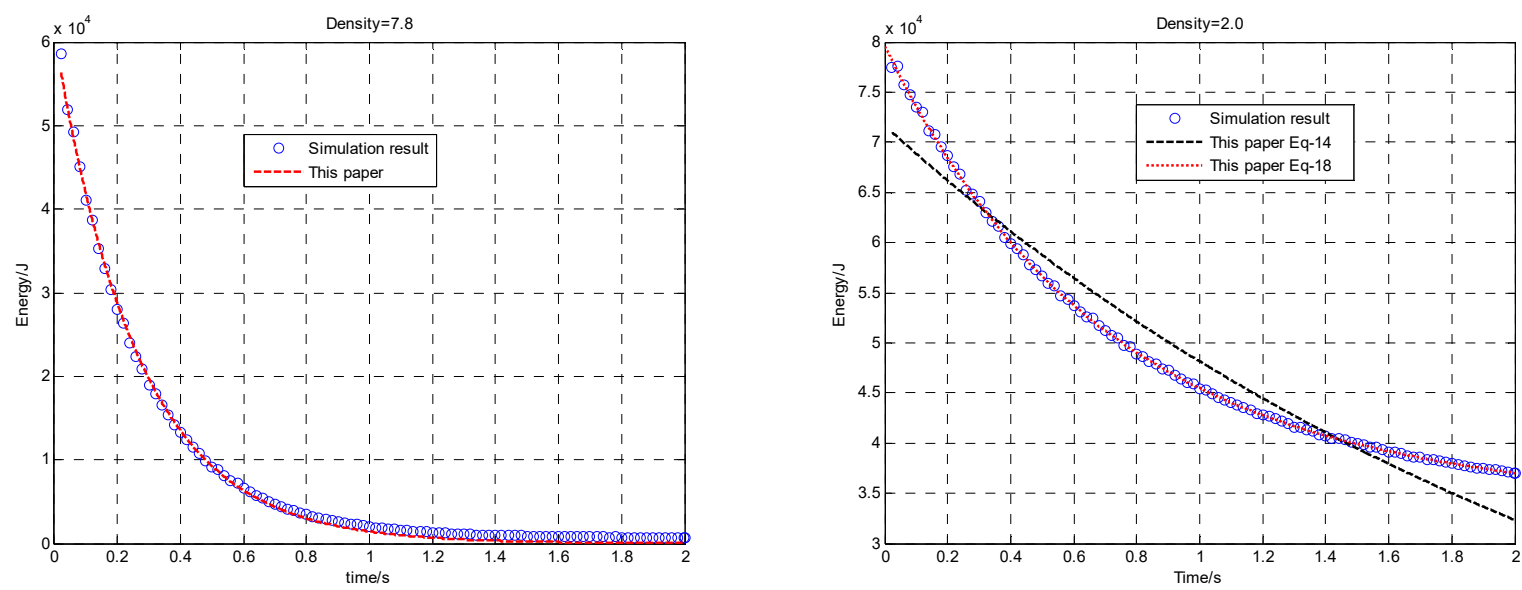

Figure 37. The plot of energy vs. time at the density $=7.8,2.0$, respectively.

Figure 38 illustrates the different mode of kinetic energy and internal energy. It can be seen from the left plot of Figure 38 that at the condition of density 7.8, the kinetic energy has the same principle to the internal energy approximately. While, at the condition of density 4.0, the internal energy is larger than the kinetic energy for the existence of plastic strain energy which cannot be transformed to kinetic energy. This means that if the structure goes into the plastic stage, the principle of energy decrease is in compliance with Equation (18) but not Equation (14). In addition, the parameters in Equation (14) can be obtained as listed in Table 6.
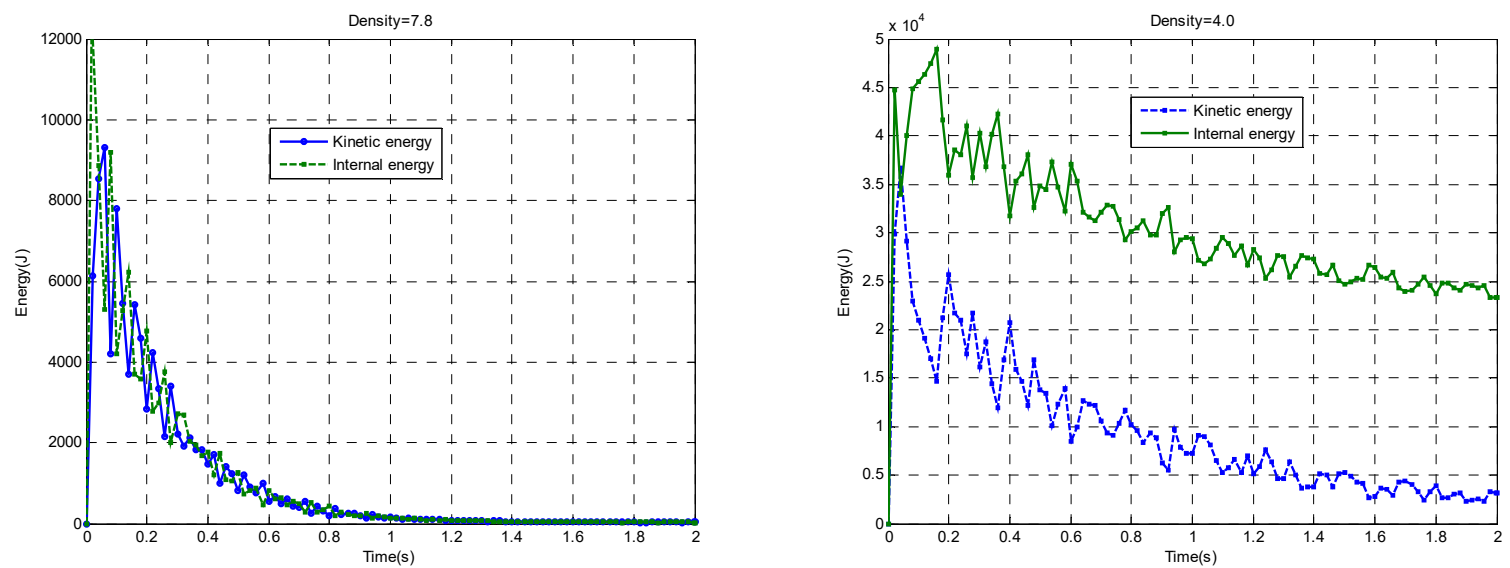

Figure 38. The comparison of internal energy and kinetic energy at density $=7.8,4.0 \mathrm{ton} / \mathrm{m}^{3}$.

Table 6. Plastic kinematic model, $E=210 \mathrm{GPa}, v=0.23, f_{y}=210 \mathrm{MPa}, E_{t}=4.0 \mathrm{GPa}$.

\begin{tabular}{|c|c|c|c|c|c|}
\hline$\rho\left(\operatorname{ton} / \mathrm{m}^{3}\right)$ & 10 & 7.8 & 4.0 & 2.0 & 1.0 \\
\hline$E_{0}\left(10^{4} \mathrm{~J}\right)$ & 5.62 & 6.08 & 7.52 & 7.86 & 8.21 \\
\hline$\beta$ & 4.63 & 3.76 & 3.12 & 1.48 & 2.75 \\
\hline$\alpha$ & / & I & 0.12 & 0.03 & 0.06 \\
\hline
\end{tabular}




\section{Conclusions}

This study establishes a new analytical model of the total initial energy and the energy responses of the hemi-cylindrical shell subjected to the explosive blast load. Both the new analytical prediction and the explicit finite element analysis were used to evaluate the energy response of the structure vibrating in the air under the external blast load by employing both analytical and numerical studies. The simulation results demonstrated that the global deformation model is classified into two types, which indicates that the detonation position is the dominant factor for the deformation models of the hemi-cylindrical shells. When the detonation position was symmetrical at the middle of the shell, the vibration frequency had several main frequencies with a high order modal shape. Correspondingly, the shell vibrated in the radial direction. When the detonation position was next to the edge of the shell, it vibrated in a main frequency with a low modal shape. Correspondingly, the shell vibrated from left to right and came back regularly.

This study is the first to demonstrate that the total initial energy which the shell can absorb in the duration of the blast is proportional inversely to the thickness of the shell. Besides, Poisson's ratio of the shell has little effect on total initial energy and the relationship to elastic modulus can be formulated as a rational function.

The key parametric studies in this paper include the thickness of the shell and the explosive detonation positions. It is found that the total energy of the shell contributed from blast load is inversely proportional to the thickness of the shell. In addition, the total energy decreases in an exponential manner respectively to time and the decrease ratio is inverse proportional to the thickness of the shell; finally, the exact formula is $\beta=\rho_{a} c / \rho_{s} T$. The thickness of shell plays a key role in both total initial energy and the decrease ratio of energy. Therefore, these insights can be useful in dealing with the design and analysis of hemi-cylindrical shell structures to resist explosive blast load.

Author Contributions: Conceptualization, P.L. and Z.-H.P.; methodology and software, P.L.; writing-original draft preparation, N.X.; writing—review and editing, P.L.; supervision Z.-H.P.

Funding: This research was funded by the National Natural Science Foundation of China (grant numbers 51508238) and by the Jiangsu Postdoctoral Research Plan (grant numbers 1601014B).

Acknowledgments: The authors are grateful for Sakdirat Kaewunruen of the University of Birmingham who revised this paper carefully and gave lots of suggestion on it.

Conflicts of Interest: The authors declare there are no conflict of interest regarding the publication of this paper.

\section{References}

1. Liu, P.; Miu, W. Added Mass of Beam Vibration on Fluid with Finite Amplitude. In Proceedings of the International Conference on Civil, Structure, Environmental Engineering (I3CSEE 2016), Guang Zhou, China, 12-13 March 2016.

2. Liu, P.; Kaewunruen, S.; Zhou, D.; Wang, S. Investigation of the Dynamic Buckling of Spherical Shell Structures Due to Subsea Collisions. Appl. Sci. 2018, 8, 1148. [CrossRef]

3. Liu, P.; Kaewunruen, S.; Tang, B. Dynamic Pressure Analysis of Hemispherical Shell Vibrating in Unbounded Compressible Fluid. Appl. Sci. 2018, 8, 1938. [CrossRef]

4. Zhang, J.; Zhang, M.; Cui, W.; Tang, W.; Wang, F.; Pan, B. Elastic-plastic buckling of deep sea spherical pressure hulls. Mar. Struct. 2018, 57, 38-51. [CrossRef]

5. Zhang, J.; Wang, M.; Cui, W.; Wang, F.; Hua, Z.; Tang, W. Effect of thickness on the buckling strength of egg-shaped pressure hulls. Ships Offshore Struct. 2018, 13, 375-384. [CrossRef]

6. Zhang, M.; Tang, W.; Wang, F.; Zhang, J.; Cui, W.; Chen, Y. Buckling of bi-segment spherical shells under hydrostatic external pressure. Thin-Walled Struct. 2017, 120, 1-8. [CrossRef]

7. Sharma, P.K.; Patel, B.P.; Lal, H. On the Response of Hemispherical Shell under Blast Loading. Procedia Eng. 2017, 173, 533-538. [CrossRef]

8. Agesh, M.; Lakshmana, R.C. Failure Analysis úof V-shaped Plates under Blast Loading. Procedia Eng. 2017, $173,519-525$. 
9. Ameijeiras, M.P.; Godoy, L.A. Simplified Analytical Approach to Evaluate the Nonlinear Dynamics of Elastic Cylindrical Shells Under Lateral Blast Loads. Lat. Am. J. Solids Struct. 2016, 13, 1281-1298. [CrossRef]

10. Hoo Fatt, M.S.; Sirivolu, D. Blast response of double curvature, composite sandwich shallow shells. Eng. Struct. 2015, 100, 696-706. [CrossRef]

11. Li, W.; Huang, G.; Bai, Y.; Dong, Y.; Feng, S. Dynamic response of spherical sandwich shells with metallic foam core under external air blast loading-Numerical simulation. Compos. Struct. 2014, 116, 612-625. [CrossRef]

12. Clubley, S.K. Long duration blast loading of cylindrical shell structures with variable fill level. Thin-Walled Struct. 2014, 85, 234-249. [CrossRef]

13. Lawrence, V.; Kaewunruen, S.; Bartoli, G.; Baniotopoulos, C. CFD simulation of passenger hazard risk at railway station platforms due to explosive air blasts. In Proceedings of the 4th Thailand Rail Academic Symposium, Khao Yai, Pakchong, Nakhon Ratchasima, Thailand, 31 August-1 September 2017.

14. Kaewunruen, S.; Pompeo, G.; Bartoli, G. Blast simulations and transient responses of longspan glass roof structures: A case of London's railway station. In Proceedings of the 25th UKACM Conference on Computational Mechanics, Birmingham, UK, 12-13 April 2017.

15. Clubley, S.K. Non-linear long duration blast loading of cylindrical shell structures. Eng. Struct. 2014, 59, 113-126. [CrossRef]

16. Jiang, J.; Qlson, M.D. New design-analysis techniques for blast loaded stiffened box and cylindrical shell structures. Int. J. Impact Eng. 1993, 13, 189-202. [CrossRef]

17. Saadin, B.; Leena, S.; Sakdirat, K.; Jaroszweski, D. Operational readiness for climate change of Malaysia high-speed rail. Proc. Inst. Civ. Eng. Transp 2016, 169, 308-320.

18. Kaewunruen, S.; Yang, T.; Xu, S. Large amplitude free vibrations of spider web structures. In Proceedings of the 29th Nordic Seminar on Computational Mechanics, Gothenburg, Sweden, 26-28 October 2016.

19. Zhai, X.; Wang, Y. Modelling and dynamic response of steel reticulated shell under blast loading. Shock Vib. 2013, 2013, 19-28. [CrossRef]

20. Ebrahimi, M.J.; Najafizadeh, M.M. Free vibration analysis of two-dimensional functionally graded cylindrical shells. Appl. Math. Model. 2014, 38, 308-324. [CrossRef]

21. Rahimi, G.H.; Ansari, R.; Hemmatnezhad, M. Vibration of functionally graded cylindrical shells with ring support. Sci. Iran. 2011, 18, 1313-1320. [CrossRef]

22. Sirivolu, D.; Hoo Fatt, M.S. Dynamic stability of double-curvature composite shells under external blast. Int. J. Non-Linear Mech. 2015, 77, 281-290. [CrossRef]

23. Pehrson, G.R.; Bannister, K.A. Airblast Loading Model for DYNA2D and DYNA3D. Army Res. Lab. 1997.

24. Bibiana Luccionia, G.A. Erosioin Criteria for Frictional Materials under Blast Load. Mec. Comput. 2011, 39, 1809-1831.

25. Hrvoje Draganić, V.S. Blast loading on structures. Djelovanje eksploz. Na Konstr. 2012, 19, 643-652.

26. Turkmen, H.S. Structureal response of laminated composite shells subjected to blast loading: Comparison of experimental and theoretical methods. J. Sound Vib. 2002, 249, 663-678. [CrossRef]

27. Santosa, S.P.; Arifurrahman, F.; Izzudin, M.H.; Widagdo, D.; Gunawan, L. Response Analysis of Blast Impact Loading of Metal-foam Sandwich Panels. Procedia Eng. 2017, 173, 495-502. [CrossRef]

28. Wikipedia. Cylindrical Coordinate System [EB/OL]. Available online: https://en.wikipedia.org/wiki/ Cylindrical_coordinate_system (accessed on 30 December 2017).

29. Wikipedia. Kirchhoff-Love Plate Theory [EB/OL]. Available online: https://en.wikipedia.org/wiki/Kirchhoff/ Love_plate_theory (accessed on 30 December 2016).

30. Wikipedia. Vibration of Plates [EB/OL]. Available online: https://en.wikipedia.org/wiki/Vibration_of_plates (accessed on 30 December 2016).

31. Tang, D.; WU, G.; YAO, X.; Wang, C. Free Vibration Analysis of Circular Cylindrical Shells with Arbitrary Boundary Conditions by the Method of Reverberation-Ray Matrix. Shock Vib. 2016, 2016, 1-18. [CrossRef]

32. Chen, X.; Ye, K. Free Vibration Analysis for Shells of Revolution Using an Exact Dynamic Stiffness Method. Math. Probl. Eng. 2016, 2016,1-12. [CrossRef]

33. Putelat, T.; Triantafyllidis, N. Dynamic stability of externally pressurized elastic rings subjected to high rates of loading. Int. J. Solids Struct. 2014, 51, 1-12. [CrossRef]

34. Johns, R.V.; Clubley, S.K. The influence of structural arrangement on long-duration blast response of annealed glazing. Int. J. Solids Struct. 2016, 97, 370-388. [CrossRef] 
35. Ma, J.L.; Wu, C.Q.; Zhi, X.D.; Fan, F. Prediction of Confined Blast Loading in Single-Layer Lattice Shells. Adv. Struct. Eng. 2014, 17, 1029-1043. [CrossRef]

36. Kumari, E.; Singha, M.K. Nonlinear Response of Laminated Panels under Blast Load. Procedia Eng. 2017, 173, 539-546. [CrossRef]

37. Caliri, M.F.; Ferreira, A.J.M.; Tita, V. A review on plate and shell theories for laminated and sandwich structures highlighting the Finite Element Method. Compos. Struct. 2016, 156, 63-77. [CrossRef]

38. Kaewunruen, S.; Sussman, J.M.; Matsumoto, A. Grand Challenges in Transportation and Transit Systems. Front. Built Environ. 2016, 2, 4. [CrossRef]

39. Kaewunruen, S. Underpinning systems thinking in railway engineering education. Australas. J. Eng. Educ. 2017, 22, 107-114. [CrossRef]

40. Gorman, D.J.; Yu, S.D. A review of the superposition method for computing free vibration eigenvalues of elastic structures. Comput. Struct. 2012, 104, 27-37. [CrossRef]

41. Qatu, M.S. Cylinderical Shells Vibration of Laminated Shells and Plates; ELsevier Academic Press: Cambridge, MA, USA, 2004; pp. 68-70.

42. Schwer, L. Air Blast Reflection Ratios and Angle of Incidence. In Proceedings of the 11th European LS-DYNA Conference, Salzburg, Austria, 9-11 May 2017.

43. Dewey, J.M. Measurement of the Physical Properties of Blast Waves. In Experimental Method of Shock Wave Research; Springer: Cham, Switzerland, 2016; Volume 33.

44. Lawrence, V.; Ngamkhanong, C.; Kaewunruen, S. An Investigation to Optimize the Layout of Protective Blast Barriers Using Finite Element Modelling. Mater. Sci. Eng. 2017, 280, 375-383. [CrossRef]

45. Vinson, J.R. The Vibration of Cylindrical Shells. In The Behavior of Thin Walled Structure: Beams, Plates and Shell; Kluwer Academic Publishers: Dordrecht, The Netherlands, 1989.

46. On the Theory of Cylindrical Shells: Explicit Solution of the Characteristic Equation, and Discussion of the Accuracy of Various Shell Theories; IABSE Publications: New York, USA, 1953.

47. Bajic, Z.; Bogdanov, J. Blast Effects Evaluation Using TNT Equivalent. Sci. Tech. Rev. 2009, 38, 50-57.

48. Díaz Alonso, F.; González Ferradás, E.; Francisco Sánchez Pérez, J.; Aznar, A.M.; Gimeno, J.R.; Alonso, J.M. Characteristic overpressure-impulse-distance curves for the detonation of explosives, pyrotechnics or unstable substances. J. Loss Prev. Process Ind. 2006, 19, 724-728.

49. Amiro, I.Y.; Prokopenko, N.Y. Study of nonlinear vibration of cylindrical shells with allowance for energy dissipatioin. Int. Appl. Mech. 1999, 35, 133-139. [CrossRef]

50. Slavik, T.P. Blast Loading Todd in LS-DYNA; Livermore Software Technology Corporation: Troy, MI, USA, 2012.

51. Brode, H.L. A Caculation of the Blast Wave for a Spherical Charge of TNT-1965; U.S. Air Force: Santa Monica, CA, USA, 1965.

52. Chao, C.C.; Tung, T.P. Step pressure and blast responses of clamped orthotropic hemispherical shell. Int. J. Impact Eng. 1989, 8, 191-207. [CrossRef]

53. Corporation, L.S.T. LS-DYNA ${ }^{\circledR}$ KEYWORD USER'S MANUAL I-VOLUMN 1; 7374 Las Positas Road Livermore, California 94551; Livermore Software Technology Corporation: Troy, MI, USA, 2017.

54. Corporation, L.S.T. LS-DYNA ${ }^{\circledR}$ KEYWORD USER'S MANUAL II-Materials Model; 7374 Las Positas Road Livermore, California 94551; Livermore Software Technology Corporation: Troy, MI, USA, 2017.

55. Jun, G.J. The experiment research on vibration characterisitcs of tensioned membrane structure. ShangXi Build. 2014, 19, 35-37.

56. Gyliene, V.; Ostasevicius, V. Cowper-Symonds material deformation law application in material cutting process using LS-DYNA FE code: Turning and milling. In Proceedings of the 8th European LS-DYNA User's Conference, Strasbourg, France, 19 May 2015.

57. Lorenzo, B.; Marco, P.; Igiovanni, P. Identification of Strain-Rate Sensitivity Parameters of Steels With an Inverse Method. Exp. Anal. Nano Eng. Mater. Struct. 2007, 558, 291-294.

58. Tan, K.T.; Huang, H.H.; Sun, C.T. Blast-wave impact mitigation using negative effective mass density concept of elastic metamaterials. Int. J. Impact Eng. 2014, 64, 20-29. [CrossRef] 
59. Yi, N.; Kim, J.J.; Han, T.; Cho, Y.G.; Lee, J.H. Blast-resistant characteristics of ultra-high strength concrete and reactive powder concrete. Constr. Build. Mater. 2011, 28, 694-707. [CrossRef]

60. Katili, I.; Batoz, J.; Maknun, I.J.; Hamdouni, A.; Millet, O. The development of DKMQ plate bending element for thick to thin shell analysis based on the Naghdi/Reissner/Mindlin shell theory. Finite Elem. Anal. Des. 2015, 100, 12-27. [CrossRef]

(C) 2019 by the authors. Licensee MDPI, Basel, Switzerland. This article is an open access article distributed under the terms and conditions of the Creative Commons Attribution (CC BY) license (http://creativecommons.org/licenses/by/4.0/). 